\title{
In Silico Designing of an Industrially Sustainable Carbonic Anhydrase Using Molecular Dynamics Simulation
}

\author{
Sachin Kumar Bharatiy, ${ }^{\dagger, \perp}$ Mousumi Hazra, ${ }^{\ddagger}, \perp$ Manish Paul, ${ }^{\S, \perp}$ Swati Mohapatra, ${ }^{\dagger}$ \\ Deviprasad Samantaray, ${ }^{\S}$ Ramesh Chandra Dubey, ${ }^{\ddagger}$ Shourjya Sanyal, ${ }^{\|}$Saurav Datta, ${ }^{*}{ }^{\dagger}$ \\ and Saugata Hazra* ${ }^{\dagger}, \#$
}

${ }^{\dagger}$ Department of Biotechnology and ${ }^{\#}$ Centre for Nanotechnology, Indian Institute of Technology Roorkee, Roorkee 247667,
Uttarakhand, India
${ }^{\ddagger}$ Department of Botany and Microbiology, Gurukula Kangri University, Haridwar 249404, Uttarakhand, India
${ }^{\S}$ Department of Microbiology, Orissa University of Agriculture and Technology, Bhubaneswar 751003, Odisha, India
${ }^{\|}$Complex and Adaptive System Laboratory, School of Physics, University College Dublin, Dublin 4, Ireland

Supporting Information

\begin{abstract}
Carbonic anhydrase (CA) is a family of metalloenzymes that has the potential to sequestrate carbon dioxide $\left(\mathrm{CO}_{2}\right)$ from the environment and reduce pollution. The goal of this study is to apply protein engineering to develop a modified CA enzyme that has both higher stability and activity and hence could be used for industrial purposes. In the current study, we have developed an in silico method to understand the molecular basis behind the stability of CA. We have performed comparative molecular dynamics simulation of two homologous $\alpha$-CA, one of thermophilic origin (Sulfurihydrogenibium sp.) and its mesophilic counterpart (Neisseria gonorrhoeae), for $100 \mathrm{~ns}$ each at $300,350,400$, and $500 \mathrm{~K}$. Comparing the trajectories of two proteins using different stability-determining factors, we have designed a highly thermostable version of mesophilic $\alpha$-CA by introducing three
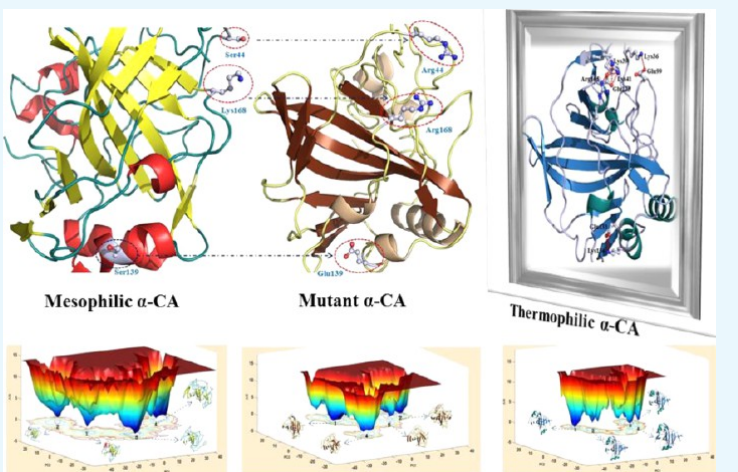
mutations (S44R, S139E, and K168R). The designed mutant $\alpha$-CA maintains conformational stability at high temperatures. This study shows the potential to develop industrially stable variants of enzymes while maintaining high activity.
\end{abstract}

\section{INTRODUCTION}

Ever-increasing concentration of $\mathrm{CO}_{2}$ is a pertinent threat, whose major contributor is flue gas from coal-fired power plants. Because of its low cost and high availability, there is a rapid increase in the usage of coal, especially in power plants. Hence, there is an urgent demand for developing techniques that would capture the generated carbon dioxide to prevent its excessive emission to the atmosphere. ${ }^{1}$ Current procedures, including amine absorption, calcium hydroxide absorption, gas separation, and so forth, are of limited or no success, due to very high energy consumption. ${ }^{2}$ Amine absorption, which is the most energy-efficient $\mathrm{CO}_{2}$ capture technology to date, is associated with around $85 \%$ "cost of electricity". This indicates that $85 \%$ of the energy generated by a coal-fired power plant will be consumed in capturing the $\mathrm{CO}_{2}$ emitted by the same power plant, making development of novel $\mathrm{CO}_{2}$ capture technology absolutely essential for the carbon-constraint world in the 21 st century. The ultimate goal of our research is to develop a biological method using enzymes to capture $\mathrm{CO}_{2}{ }^{3,4}$

In nature, bacteria transforms $\mathrm{CO}_{2}$ to bicarbonate at physiological $\mathrm{pH}$, using the carbonic anhydrase (CA) class of enzymes as catalysts. ${ }^{5-7} \mathrm{CA}$ is a family of zinc-containing metalloenzymes that stimulates the interconversion of carbon dioxide $\left(\mathrm{CO}_{2}\right)$ and water into bicarbonate and proton, ${ }^{8-10}$ and hence, this enzyme helps in transporting $\mathrm{CO}_{2}$ in the form of water-soluble bicarbonate. ${ }^{11,12}$

$$
\begin{aligned}
& \mathrm{CO}_{2}+\mathrm{H}_{2} \mathrm{O} \rightleftarrows \mathrm{H}_{2} \mathrm{CO}_{3} \\
& \mathrm{H}_{2} \mathrm{CO}_{3} \rightleftarrows \mathrm{H}^{+}+\mathrm{HCO}_{3}^{-}
\end{aligned}
$$

Therefore, the above-mentioned enzymatic mechanism can be used in tackling the pollution problem caused by the emission of $\mathrm{CO}_{2}$ from industries. ${ }^{13,14} \mathrm{CA}$ is found ubiquitously in prokaryotic microorganisms (bacteria), algae, plants as well as in higher eukaryotic animals. There are five classes of evolutionary distinct CAs, namely, $\alpha, \beta, \gamma, \delta$, and $\zeta$. All of these classes are found in bacteria, ${ }^{15,16}$ except for the $\delta$ class, which is found in diatoms. These different classes of CAs share very low sequence identity and have different structural folds (Figures 1 and S1). Differences in sequence homology and structure along with identity in function make CA an ideal example of convergent evolution. ${ }^{17,18}$ To adapt with environ-

Received: May 6, 2016

Accepted: September 15, 2016

Published: December 5, 2016 
(a)
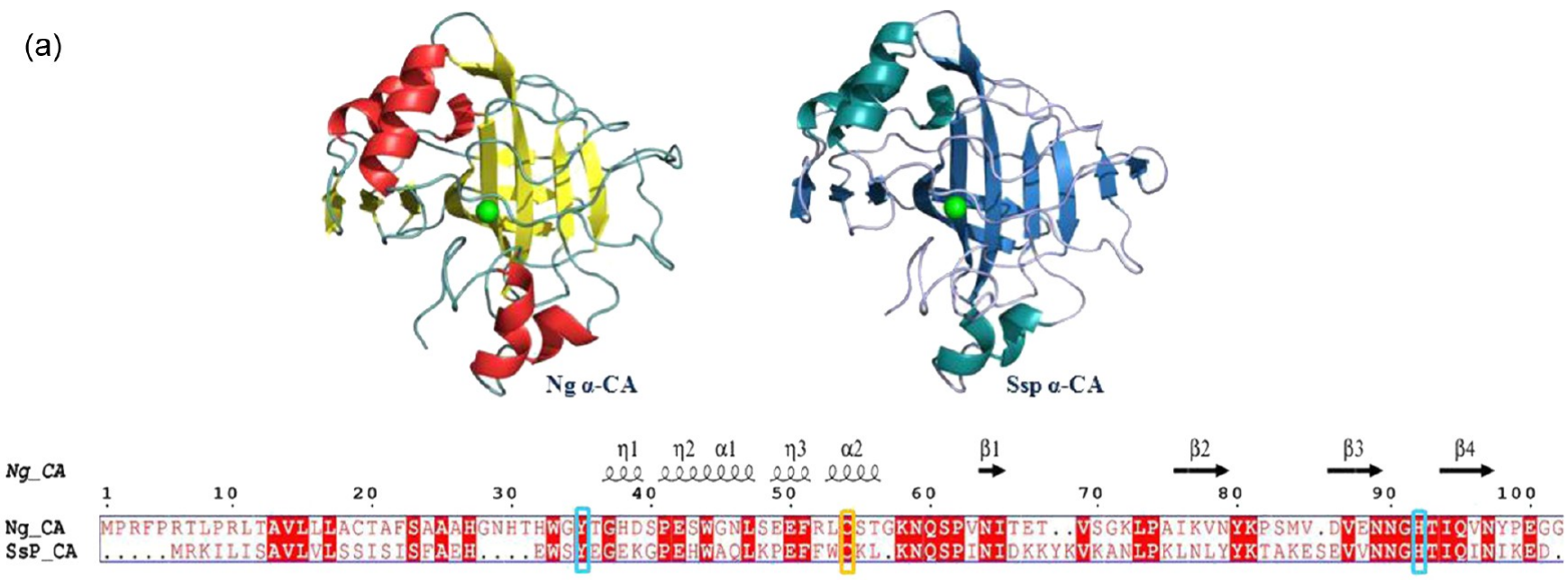

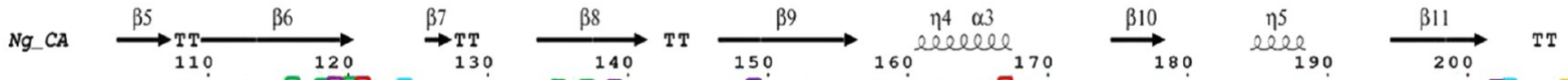

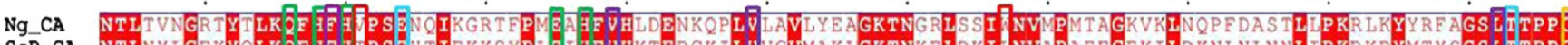

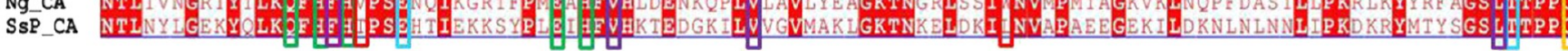

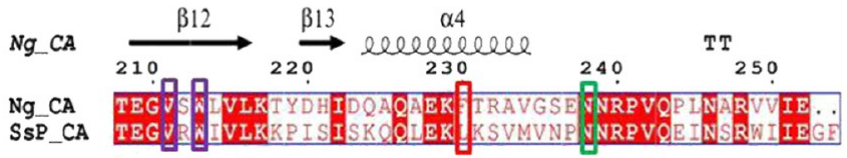

(b)
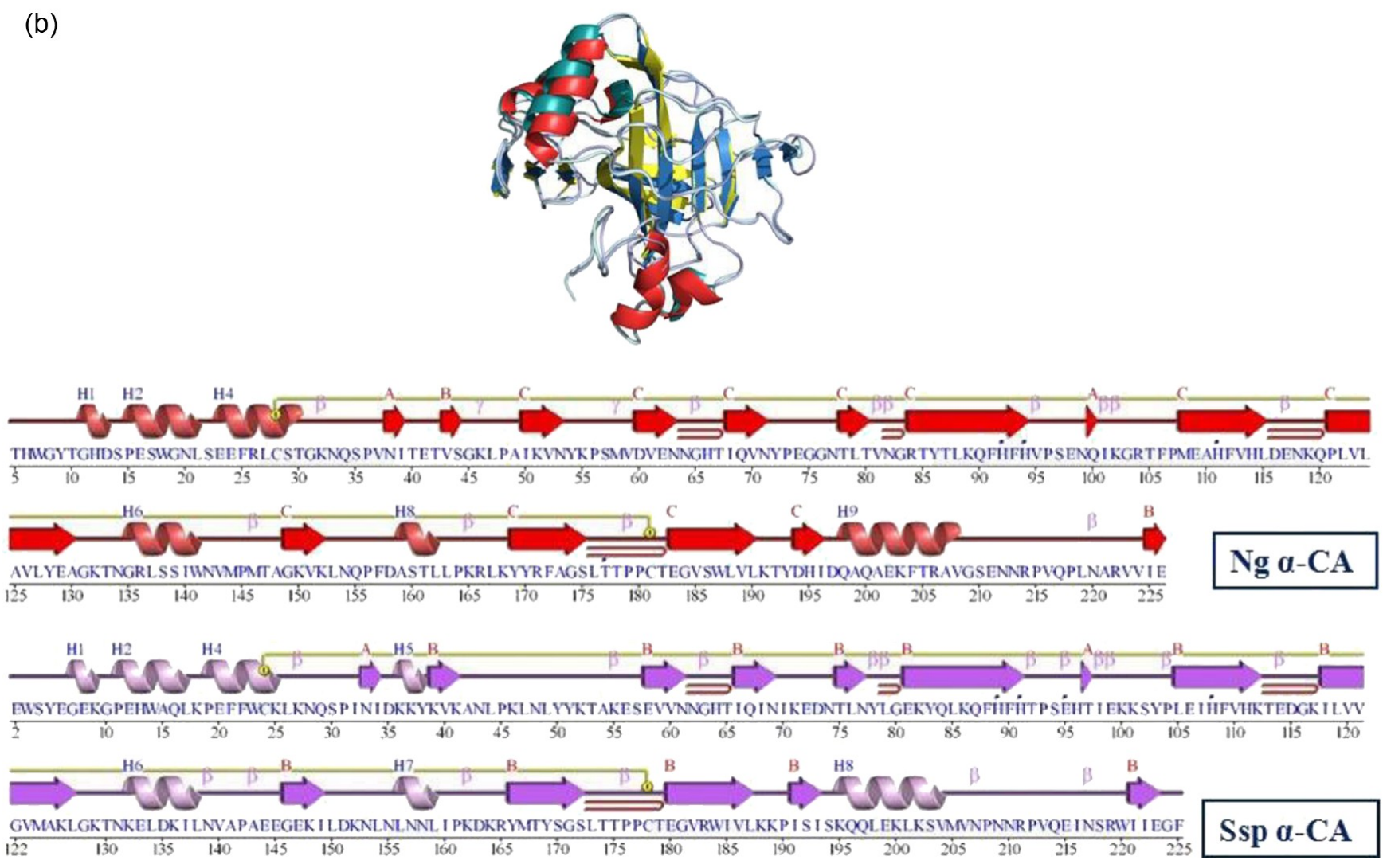

Figure 1. a. Cartoon representation and sequence alignment of $\mathrm{Ng} \alpha$-CA and $\operatorname{Ssp} \alpha$-CA, b. Structural alignment of $\mathrm{Ng} \alpha$-CA and Ssp $\alpha$-CA. These two alignments clearly show the presence of similarity in the protein tertiary structure in spite of differences in the amino acid sequence.

mental changes, different classes of CAs change their overall secondary structure without altering their active site. All of these classes are of ancient origin and appear to have evolved independently from one another, having a zinc metal ion in their active site. $\alpha$-CA has three conserved histidine residues in the active site (Figure S2). ${ }^{19,20}$ 


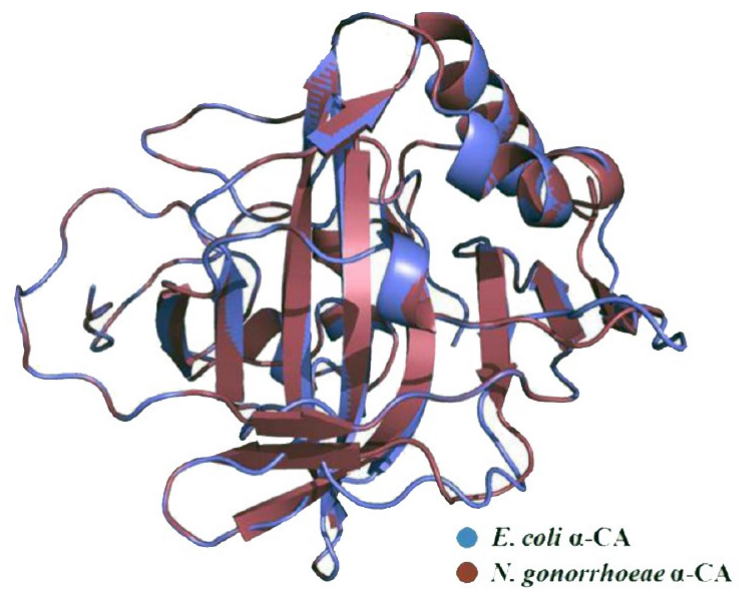

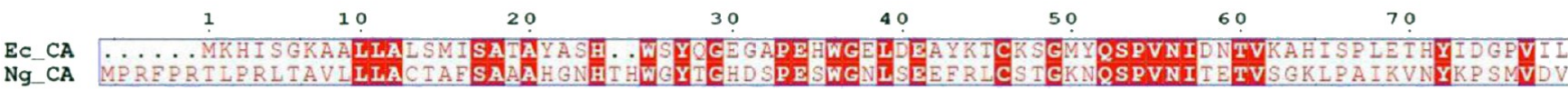

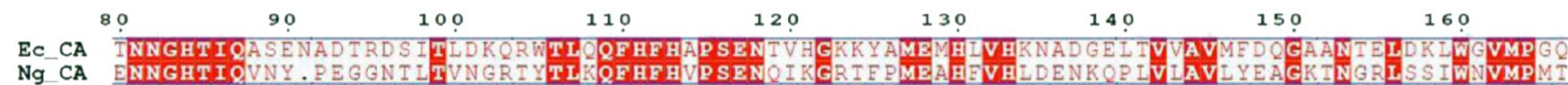

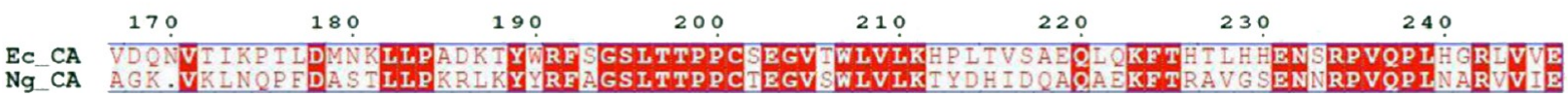

Figure 2. Sequence (left) and structure (right) alignments between E. coli and N. gonorrhoeae $\alpha$-CA. Remarkable similarities have been observed from both sequence and structural points of view.

In this study, we have chosen prokaryotic $\alpha$-CAs, as they are inexpensive as well as easily available for experimental validation and concurrent production using cell lines. One of the major requirements to make the project successful is the productivity of the enzyme. To develop the protein, we depend on an Escherichia coli-based bacterial expression system for simple reasons: E. coli (1) is well characterized, (2) has a faster growth rate, and (3) requires optimized growth conditions both in shake flasks and bioreactors. Thus, there is a need for selecting a CA of mesophilic origin. We have selected $\alpha$-CA from Neisseria gonorrhoeae because of its mesophilic origin, considering that it would be better to express the protein in the E. coli expression system. In addition to this, $\alpha$-CA from $N$. gonorrhoeae has a high sequence identity and a structure nearly similar to that of $E$. coli $\alpha$-CA (Figure 2). Moreover, there are also some other attributes for choosing a mesophilic model compared to a thermophilic one. Besides the similarity of $\alpha$-CA between N. gonorrhoeae and E. coli, both organisms are Gram-negative and inhabit similar types of environments, which further supports our choice of mesophilic systems.

$\alpha$-CAs are among the fastest catalyzing enzymes; however, one of the biggest challenges of using them in industries is that they are not stable enough to withstand the harsh environment found in the power plant exhaust. We have taken a highly interdisciplinary approach including in silico techniques followed by genetic engineering to develop an industrially stable, engineered $\alpha$-CA that can tolerate harsh operating conditions (in terms of temperature and $\mathrm{pH}$ ) typically encountered in $\mathrm{CO}_{2}$ capture processes for power plant flue gas. The engineered enzyme could be immobilized to a membrane, and the enzyme-tagged membrane could be used as a nanodevice to sequester carbon dioxide from the flue gas outlet of the power plant.

In this study, our goal is to design a mesophilic $\alpha$-CA $(N$. gonorrhoeae) with higher thermal stability while retaining its enzyme activity. To gain insight into the unfolding mechanism prior to the rationally designing the mutations, comparative molecular dynamics (MD) simulations were performed on the mesophilic $\alpha$-CA (N. gonorrhoeae $)^{21}$ and a thermophilic $\alpha$-CA (Sulfurohydrogenibium sp.) $)^{22,23}$ at temperatures of 300, 350, 400, and $500 \mathrm{~K}$, each for $100 \mathrm{~ns}$. Using MD simulation trajectories, different stability-determining variables such as root-meansquare deviation (RMSD), root-mean-square fluctuation (RMSF), radius of gyration $\left(R_{\mathrm{g}}\right)$, solvent-accessible surface area (SASA), hydrogen bonds, salt bridges, ${ }^{24-28}$ unfolding pathway, principal component analysis (PCA), and free-energy landscape (FEL) were analyzed. ${ }^{29,30}$ On the basis of the analyzed results, by comparing differences in those analyses of stability-determining factors, ${ }^{31-34}$ a mutant variant of mesophilic $\alpha$-CA was designed, containing the variant residues: S44R, S139E, and K168R (Figure 3). This was followed by MD simulations at the above-mentioned temperatures for the designed mutant. Analysis not only reveals a sharp increase in the stability of the engineered variant of $\alpha$-CA but also predicts the stability to be comparable to that of the thermophilic homologue. ${ }^{35,36}$ This study would be a good platform for 

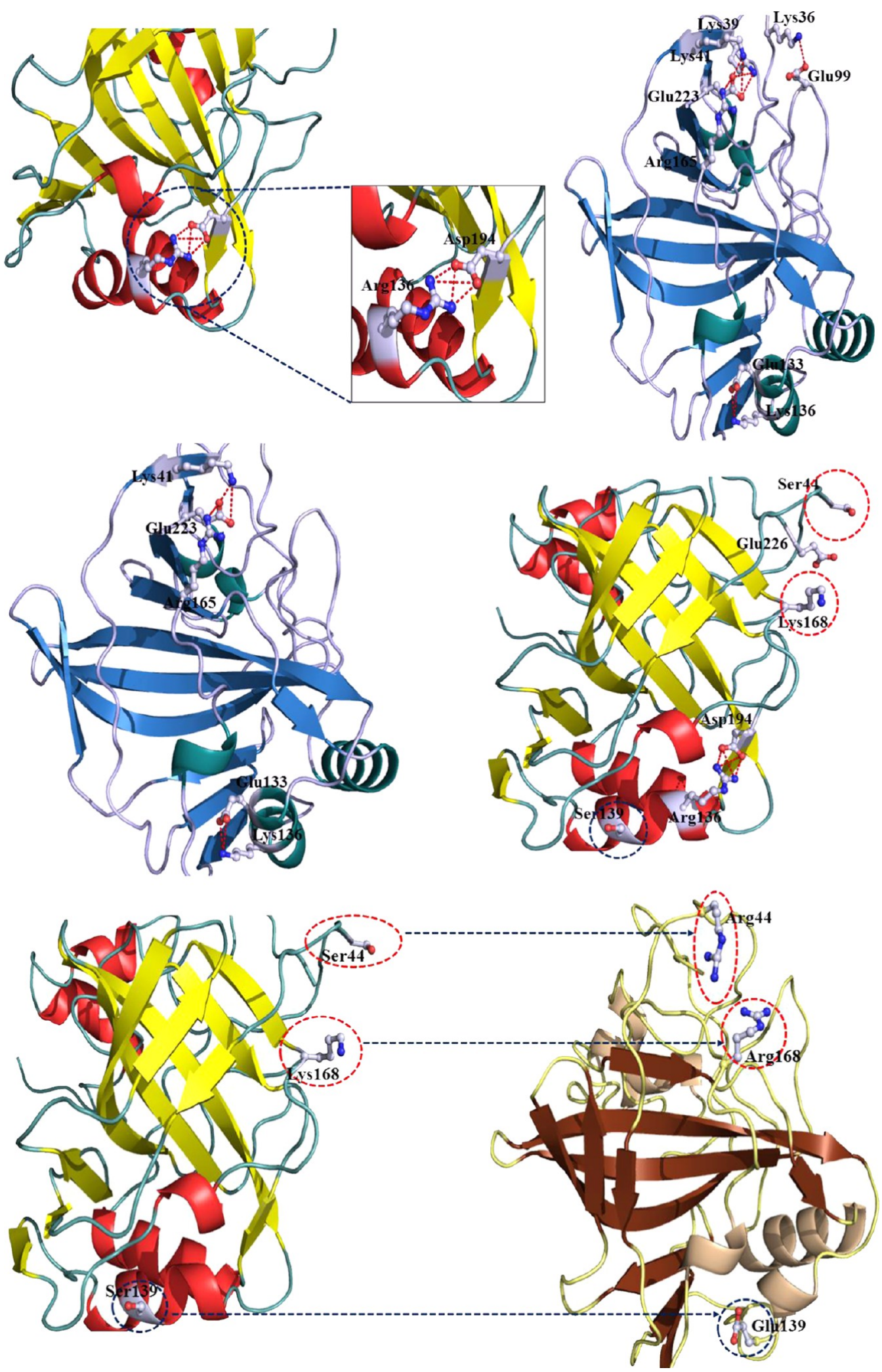

Figure 3. continued 


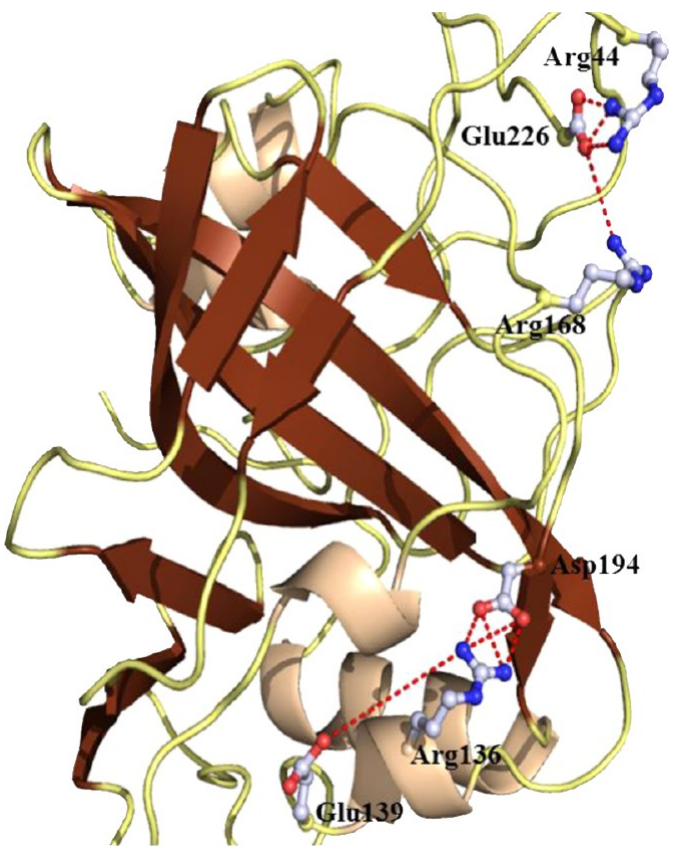

Figure 3. The structure with $\beta$ sheets in yellow is mesophilic $\operatorname{Ng} \alpha$-CA, and the structure with $\beta$ sheets in blue is thermophilic Ssp $\alpha$-CA. On the basis of our comparative analysis of the distribution of salt bridges in these two structures and their effect on stability, we have designed a mutant variant of mesophilic $\mathrm{Ng} \alpha$-CA, whose $\beta$ sheets are shown in brown.

experimentally designing a construct to develop a thermostable variant of industrially important enzyme.

\section{RESULTS AND DISCUSSION}

Salt Bridge Analysis. The bonds formed between the negatively charged side chains of aspartic or glutamic acid and the positively charged side chain of lysine or arginine are salt bridges, which stabilize the secondary structure of proteins. The stability increases with both increased number of salt bridges and the reduced distance between two salt bridge-forming side chains.

In Ssp $\alpha$-CA, there are five salt bridges: ${ }^{\text {Lys } 36}{ }^{\mathrm{NZ}}-{ }^{\mathrm{Glu}}{ }^{\circ} \mathrm{OE}_{1}$, ${ }^{\mathrm{Lys} 41} \mathrm{NZ}-{ }^{\mathrm{Glu} 223} \mathrm{OE}_{1},{ }^{\mathrm{Lys} 39} \mathrm{NZ}-{ }^{\mathrm{Glu} 223} \mathrm{OE}_{1},{ }^{\text {Lys136 }} \mathrm{NZ}-{ }^{\mathrm{Glu} 133} \mathrm{OE}_{1}$, and ${ }^{\operatorname{Arg} 165} \mathrm{NH}_{2}-{ }^{\mathrm{Glu} 223} \mathrm{OE}_{1}$. In place of these salt bridges, $\mathrm{Ng} \alpha$-CA has four salt bridges: ${ }^{\operatorname{Arg} 136} \mathrm{NH}_{1}-{ }^{\mathrm{Asp} 194} \mathrm{OD}_{1},{ }^{\operatorname{Arg} 136} \mathrm{NH}_{1}-{ }^{\mathrm{Asp} 194} \mathrm{OD}_{2}$, ${ }^{A r g 136} \mathrm{NH}_{2}-{ }^{\mathrm{Asp} 194} \mathrm{OD}_{1}$, and ${ }^{\mathrm{Arg} 136} \mathrm{NH}_{2}-{ }^{\mathrm{Asp} 194} \mathrm{OD}_{2}$. In $\mathrm{Ng} \alpha$-CA, these salt bridges are responsible only for the local stabilization of $\mathrm{Ng} \alpha$-CA; however, in the case of Ssp $\alpha$-CA, four salt bridges are shown to stabilize a specific domain of the protein and the remaining one stabilizes another domain. In Ssp $\alpha$-CA, there are a total of eight residues involved in salt bridge formation. $\mathrm{MD}$ simulations show that the salt bridges of Ssp $\alpha$-CA maintain an overall fixed length throughout all of the temperature simulations. But in the case of $\mathrm{Ng} \alpha$-CA, the salt bridge lengths vary in a broad range and they are very unstable. The stable salt bridges in Ssp $\alpha$-CA are majorly responsible for its greater thermostability compared to $\mathrm{Ng} \alpha$-CA.

On the basis of these observations, we have introduced three mutations in mesophilic $\mathrm{Ng} \alpha$-CA. From sequence and structure alignment, we have found that the residues Lys41, Glu136, and $\operatorname{Arg} 165$ form salt bridges in thermophilic $\alpha$-CA, whereas they are absent in its mesophilic counterpart. Mesophilic $\mathrm{Ng} \alpha$-CA contains Ser44, Ser139, and Lys168 in place of those salt bridgeforming residues. From this observation, we have designed a mutant variant consisting of S44R, S139E, and K168R. As a result, the mutant variant contains five new salt bridges. Glu226 in the mutant variant is involved in forming four salt bridges with Arg44 and Arg168. Another salt bridge is formed between Glu139 and Arg136. So, the mutant variant now contains a total of nine salt bridges, resulting in enhanced stability compared to its thermophilic counterpart.

We have analyzed the salt bridge length variation of all of the CA systems at four different simulation temperatures (300, 350, 400 , and $500 \mathrm{~K}$ ) (Figure 4, Table 1). We have found that the lengths of all of the salt bridges for mesophilic $\alpha$-CA fluctuate considerably, and at high temperatures, the salt bridges become destabilized. At $300 \mathrm{~K}$, the salt bridge-forming residues (Arg136 and Asp194) of $\mathrm{Ng} \alpha$-CA are located at $\alpha 3$ and $\beta 11$. With increasing temperature, the $\beta 11$ secondary structure disintegrates, making Asp194 flexible. This causes weakening of the Arg136-Asp194 salt bridge. In addition, it stimulates the loss of an $\alpha 3$ secondary structure imposing instability to Arg136. These cumulative effects make the Arg136-Asp194 salt bridge fully unstable at $500 \mathrm{~K}$.

In the case of thermophilic $\alpha$-CA, all of the five salt bridges remain stabilized and the lengths of the four salt bridges, Lys36-Glu99, Lys39-Glu223, Arg165-Glu223, and Lys136Glu133, remain unchanged for all four temperature simulations. It has also been observed that three salt bridge-forming residues of Ssp $\alpha$-CA, Lys39, Lys41, and Glu223 remain in the loop at $300 \mathrm{~K}$ but occupy $\beta 1$ and $\beta 11$ secondary structures at higher temperatures $(350,400$, and $500 \mathrm{~K})$. It can be concluded that it is this strong interaction and the salt bridge network between these three residues that help in the formation of the secondary structure in the thermophilic protein. Also the two residues, Glu133-Lys136, which form a salt bridge, maintain the stability of the $\alpha$-helix in which they reside.

In the mutant variant, three modified residues, S44R, S139E, and $\mathrm{K} 168 \mathrm{R}$, resulted in five new salt bridge interactions ( ${ }^{\text {rg }}{ }^{44} \mathrm{NH} 1-{ }^{\mathrm{Glu}} 226 \mathrm{OE} 2,{ }^{\mathrm{Arg}}{ }^{44} \mathrm{NH} 2-\mathrm{Glu} 226 \mathrm{OE} 2$, $\operatorname{Arg} 1{ }^{68} \mathrm{NH} 1-{ }^{\mathrm{Glu} 226} \mathrm{OE} 1, \operatorname{Arg} 168 \mathrm{NH} 2-\mathrm{Glu} 226 \mathrm{OE} 1$, and $\left.{ }^{A r g}{ }^{136} \mathrm{NH} 1-{ }^{\text {Glu139 }} \mathrm{OE} 2\right)$. These five new salt bridges show extra 
(a)
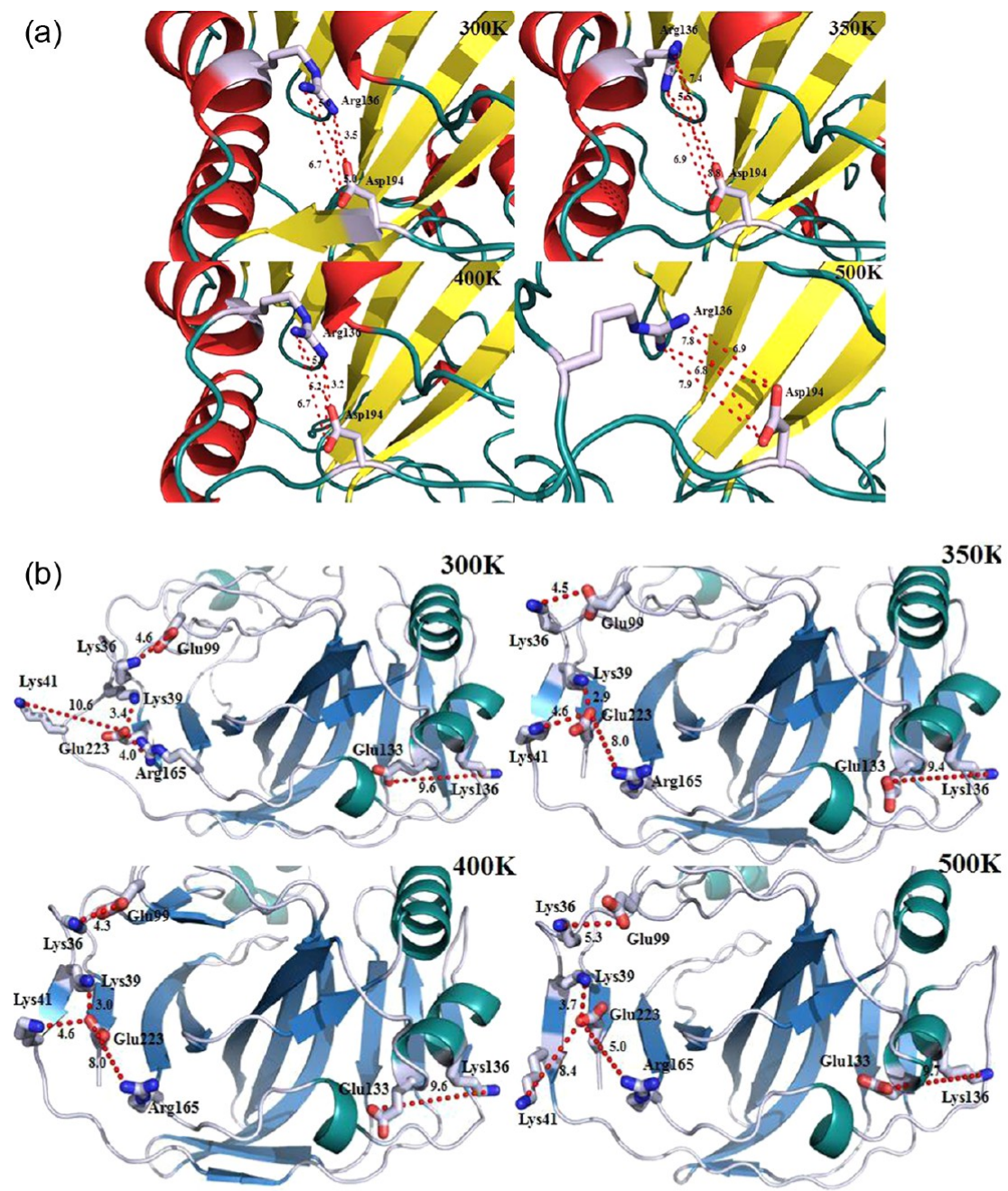

(c)

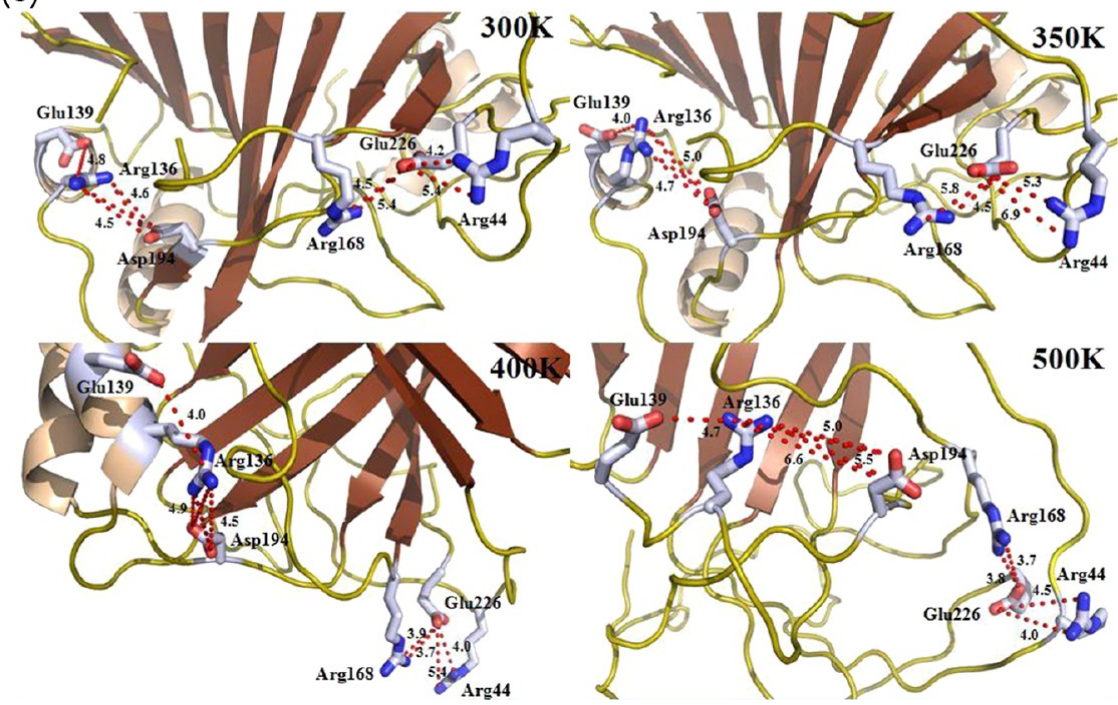

Figure 4. Salt bridge length comparison of a. $\mathrm{Ng} \alpha$-CA, b. Ssp $\alpha$-CA, and c. mutant $\mathrm{Ng} \alpha$-CA. a. $\mathrm{Ng} \alpha$-CA: salt bridge interaction happens between two residues; Arg136-Asp194. Lengths increase significantly with increasing temperature. b. Ssp $\alpha$-CA: Different sets of residues forming salt bridges all over the protein. The length of bridges remains intact or minor changes happen even in higher temperature simulations. c. mutant $\mathrm{Ng} \alpha$-CA: Change in three residues results in several new salt bridges; as in Ssp-CA, the length remains intact at higher temperatures.

stability at all four temperatures. In particular, the salt bridges formed between mutant residues Arg44 and Arg168 with Glu226 remain significantly stable even at 400 and $500 \mathrm{~K}$. Salt bridges between Arg136 and Asp194, which are common in both the wild-type and mutant variants, show differences in bond length (6.6 and 4.0 Å respectively). Another stabilized salt bridge in mutant $\alpha$-CA (Arg136-Glu39) is found to maintain its length within 4.0-4.9 Å throughout all temperature simulations. 
Table 1. Salt Bridges in $\alpha$-CA and Their Length Variation at Different Simulation Temperatures

\begin{tabular}{|c|c|c|c|c|c|}
\hline & \multirow[b]{2}{*}{ salt bridge } & \multicolumn{4}{|c|}{ distance $(\AA)$} \\
\hline & & $300 \mathrm{~K}$ & $350 \mathrm{~K}$ & $400 \mathrm{~K}$ & $500 \mathrm{~K}$ \\
\hline \multirow[t]{4}{*}{ mesophilic $\alpha$-CA } & ${ }^{\operatorname{Arg} 136} \mathrm{NH} 1-{ }^{\mathrm{Asp} 194} \mathrm{OD} 1$ & 5.0 & 8.8 & 5.0 & 6.8 \\
\hline & ${ }^{\mathrm{Arg} 136} \mathrm{NH} 1-{ }^{\mathrm{Asp} 194} \mathrm{OD} 2$ & 6.7 & 6.9 & 3.2 & 6.9 \\
\hline & ${ }^{\operatorname{Arg} 136} \mathrm{NH} 2-{ }^{\mathrm{Asp} 194} \mathrm{OD} 1$ & 3.5 & 7.4 & 6.7 & 7.9 \\
\hline & ${ }^{\mathrm{Arg} 136} \mathrm{NH} 2-{ }^{\mathrm{Asp} 194} \mathrm{OD} 2$ & 5.6 & 5.5 & 5.2 & 7.8 \\
\hline \multirow[t]{5}{*}{ thermophilic $\alpha$-CA } & ${ }^{\text {Lys36 }} \mathrm{NZ}-{ }^{\text {Glu99}} \mathrm{OE} 1$ & 4.6 & 4.5 & 4.3 & 5.3 \\
\hline & ${ }^{\text {Lys } 41} \mathrm{NZ}-{ }^{\mathrm{Glu} 223} \mathrm{OE} 1$ & 10.6 & 4.6 & 4.6 & 8.4 \\
\hline & ${ }^{\text {Lys } 39} \mathrm{NZ}-{ }^{\mathrm{Glu}} 223 \mathrm{OE} 1$ & 3.4 & 2.9 & 3.0 & 3.7 \\
\hline & ${ }^{\text {Lys } 136} \mathrm{NZ}-{ }^{\mathrm{Glu} 133} \mathrm{OE} 1$ & 9.6 & 9.4 & 9.6 & 9.7 \\
\hline & ${ }^{\operatorname{Arg} 165} \mathrm{NH} 2-{ }^{\mathrm{Glu} 223} \mathrm{OE} 1$ & 4.0 & 8.0 & 8.0 & 9.0 \\
\hline \multirow[t]{9}{*}{ meso_mutant $\alpha$-CA } & ${ }^{\mathrm{Arg} 136} \mathrm{NH} 1-{ }^{\mathrm{Asp} 194} \mathrm{OD} 1$ & 4.6 & 5.0 & 4.5 & 5.0 \\
\hline & ${ }^{\operatorname{Arg} 136} \mathrm{NH} 1-{ }^{\mathrm{Asp} 194} \mathrm{OD} 2$ & 4.6 & 4.1 & 7.7 & 4.0 \\
\hline & ${ }^{\mathrm{Arg} 136} \mathrm{NH} 2-{ }^{\mathrm{Asp} 194} \mathrm{OD} 1$ & 4.8 & 4.5 & 3.9 & 5.5 \\
\hline & ${ }^{\operatorname{Arg} 136} \mathrm{NH} 2-{ }^{\mathrm{Asp} 194} \mathrm{OD} 2$ & 4.5 & 4.7 & 4.9 & 6.6 \\
\hline & ${ }^{\mathrm{Arg}}{ }^{44} \mathrm{NH} 1-{ }^{\mathrm{Glu} 226} \mathrm{OE} 2$ & 5.4 & 6.9 & 5.4 & 4.0 \\
\hline & ${ }^{\mathrm{Arg}}{ }^{44} \mathrm{NH} 2-{ }^{\mathrm{Glu} 226} \mathrm{OE} 2$ & 4.2 & 5.3 & 4.0 & 4.5 \\
\hline & ${ }^{\operatorname{Arg} 168} \mathrm{NH} 1-{ }^{\mathrm{Glu} 226} \mathrm{OE} 1$ & 4.5 & 4.5 & 3.9 & 3.8 \\
\hline & ${ }^{\operatorname{Arg} 168} \mathrm{NH} 2-{ }^{\mathrm{Glu} 226} \mathrm{OE} 1$ & 5.4 & 5.8 & 3.7 & 3.7 \\
\hline & ${ }^{\mathrm{Arg} 136} \mathrm{NH} 1-{ }^{\mathrm{Glu} 139} \mathrm{OE} 2$ & 4.8 & 4.0 & 4.0 & 4.7 \\
\hline
\end{tabular}

From the MD study of average salt bridge length of all of the $\alpha$-CA systems, it is evident that more number of strong and comparatively stable salt bridges in both thermophilic and mutant $\alpha$-CA are responsible for their greater thermal adaptability compared to the mesophilic one. These stable salt bridges are also important for retaining the local secondary structure content in thermophilic and mutant $\alpha$-CA. Modified residues in mutant $\alpha$-CA form extra salt bridges, resulting in a further increase in stability compared to the mesophilic $\alpha$-CA, as supported by other analyses such as RMSD, RMSF, PCA, and FEL.

Hydrogen Bonding Pattern. Like salt bridges, hydrogen bonds are also important for maintaining the protein secondary structure. Hydrogen bond from two different residues remains connected with each other within $3.5 \AA$. In this study, we have considered two different types of hydrogen bonds: (a) intramolecular hydrogen bonds (protein-protein) and (b) intermolecular hydrogen bonds (protein-solvent) (Table S1).

Intramolecular Hydrogen Bonds. This type of hydrogen bond is responsible for maintaining the protein integrity and helps in increasing the protein thermostability. With an increase in temperature, the number of intramolecular hydrogen bonds decreases, and the protein becomes unstable. The average number of intramolecular hydrogen bonds in mesophilic and thermophilic $\alpha$-CA are 168.20, 168.84, 160.62, and 145.50 and $163.20,164.19,163.65$, and 154.07 , respectively at 300,350 , 400 , and $500 \mathrm{~K}$. The number of hydrogen bonds that maintain the protein integrity decreases rapidly in the case of mesophilic CA compared to the thermophilic one. This clearly depicts the importance of intramolecular hydrogen bonds in maintaining the protein thermostability. Mutant CA shows an even higher average number of hydrogen bonds at $300 \mathrm{~K}$ (170.18), which is nearly maintained up to 350 and $400 \mathrm{~K}$ (162.78 and 161.64). The number of average intramolecular hydrogen bonds in the mutant also decreases to 148.72 , which is higher than that in the case of mesophilic CA at $500 \mathrm{~K}$ (145.50). These values of intramolecular hydrogen bonds suggest that the mutant gains extra stability due to the induced mutations (Table S1). A salt bridge is the crucial reason here for the stability of those hydrogen bonds in mutant $\alpha$-CA. Five additional salt bridges were observed in the mutant variant compared to mesophilic $\mathrm{Ng}$ $\alpha$-CA $\left({ }^{\mathrm{Arg}}{ }^{44} \mathrm{NH} 1-{ }^{\mathrm{Glu} 226} \mathrm{OE} 2,{ }^{\mathrm{Arg} 44} \mathrm{NH} 2-{ }^{\mathrm{Glu} 226} \mathrm{OE} 2\right.$, $\operatorname{Arg} 168 \mathrm{NH} 1-{ }^{\mathrm{Glu} 226} \mathrm{OE} 1,{ }^{\operatorname{Arg} 168} \mathrm{NH} 2-{ }^{\mathrm{Glu} 226} \mathrm{OE} 1$, and $\left.{ }^{A r g} 136 \mathrm{NH} 1-{ }^{\text {Glu139 }} \mathrm{OE} 2\right)$. But a more important factor is the position of those salt bridges. They are distributed in the protein rather than being on one particular side and bringing the loops together (Figure S9). This distribution helps the protein to hold the entire structural architecture, especially at higher temperatures, enhancing stability.

Intermolecular Hydrogen Bonds. Intermolecular hydrogen bonds maintain the interactions between the protein and solvent. The interaction between the protein and solvent molecule increases when the hydrophobic core region of the protein gradually becomes unwrapped with its unfolding. Surfacing of the hydrophobic region of protein increases the affinity of the protein core to the solvent molecule. The average number of intermolecular hydrogen bonds in mesophilic and thermophilic $\alpha$-CA are 465.94, 432.88, 388.79, and 303.38 and $510.85,457.73,412.06$, and 319.65 , respectively. The decrease in the number of intermolecular hydrogen bonds is less in the case of mesophilic CA compared to its thermophilic counterpart across the entire range of temperatures. Increased temperature also causes the loss of intermolecular H-bonding in a proteinsolvent system even when the protein gradually unwraps from its native state to an unfolded state. The number of proteinsolvent intramolecular hydrogen bonds rapidly decreases in the case of a comparatively stable protein, as we can see in the case of Ssp $\alpha$-CA and mutant $\mathrm{Ng} \alpha$-CA. In such cases, fewer protein residues remain free for interacting with the solvent and hence they are able to retain more secondary content even at a high temperature. But in the case of mesophilic protein such a rapid decrease in intramolecular H-bonds is not usual. So, residues in the relatively less stable mesophilic $\mathrm{Ng} \alpha$-CA remain bound to solvent molecules through intramolecular H-bonds. This phenomenon causes structural instability of mesophilic $\mathrm{Ng} \alpha$ $\mathrm{CA}$ at high temperatures. In the case of the mutant, average values of intermolecular hydrogen bonds are 467.05, 434.24, 396.30 , and 301.46, respectively, for $300,350,400$, and $500 \mathrm{~K}$. So, the decrease in the number of average intermolecular hydrogen bonds observed in thermophilic and mutant proteins 
(a)

Ons
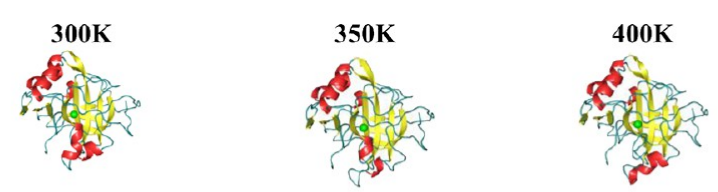

$500 \mathrm{~K}$

10ns
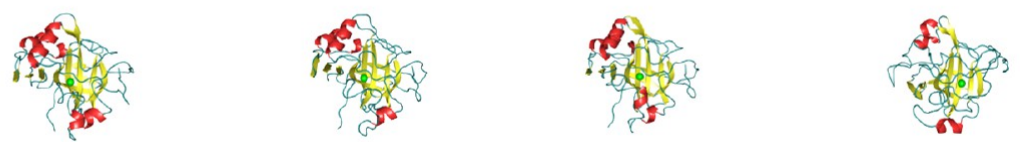

20ns
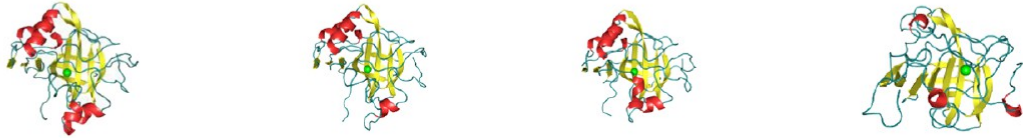

30ns
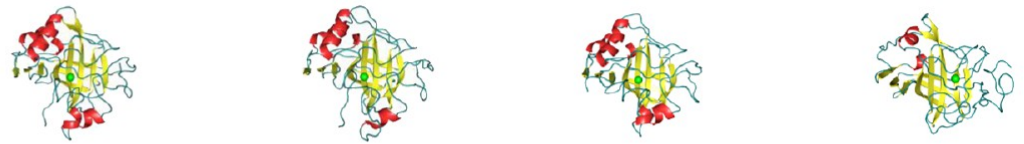

40ns
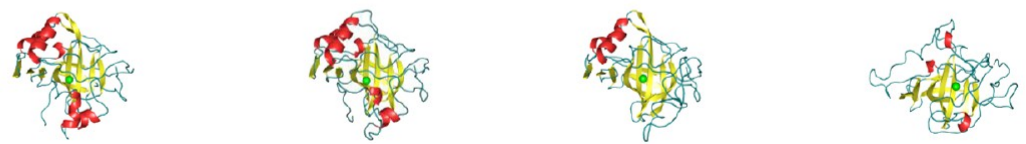

$50 \mathrm{~ns}$
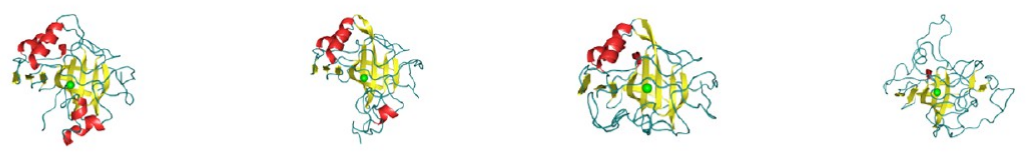

60ns
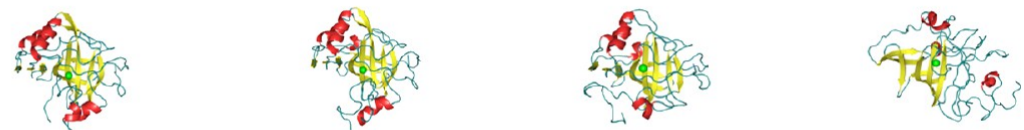

70ns
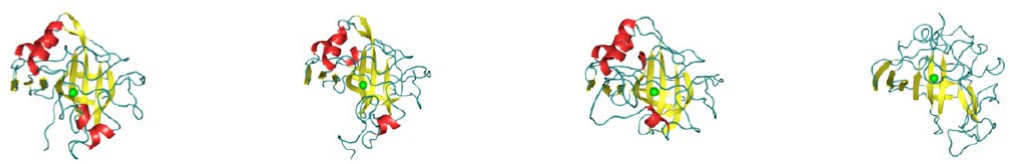

80ns
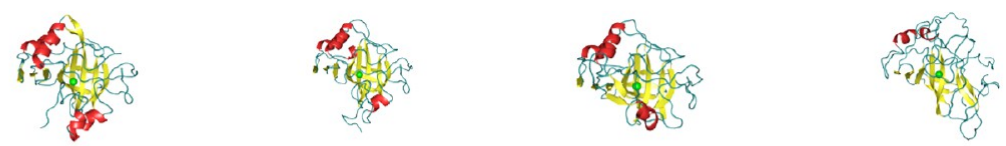

90ns
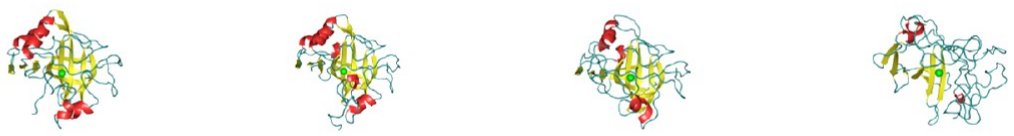

$100 \mathrm{~ns}$
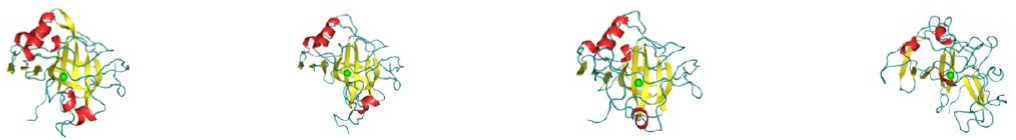

Figure 5. continued 
(b) ons

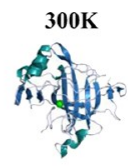

$10 n s$

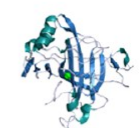

20ns<smiles>[C+]1CC1</smiles>

30ns<smiles>C1CCC(C2CCC2)C1</smiles>

40ns<smiles>c1ccc(Sc2nccs2)cc1</smiles>

50ns<smiles>[C]1C2CC1C2</smiles>

$60 \mathrm{~ns}$

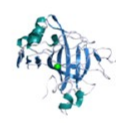

70ns

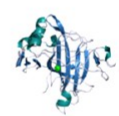

80ns<smiles></smiles>

90ns

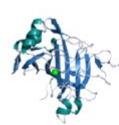

100ns

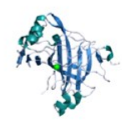

(c) ons

300K

10ns

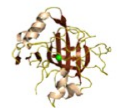

20ns
(1)

ind

ind

sto

का

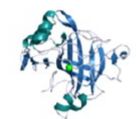

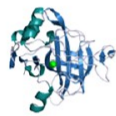

सी
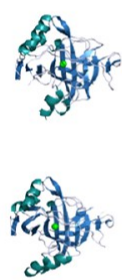

cole
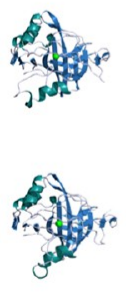

350K

जी

कोण
$400 \mathrm{~K}$

rifle

ing

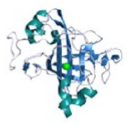

ही
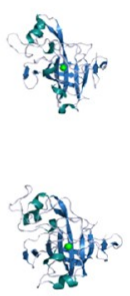

og
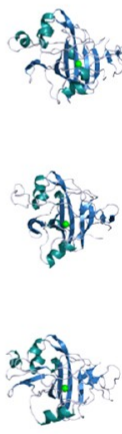

敖

解

,

त्र

.

Figure 5. continued 
30ns

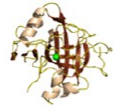

40ns

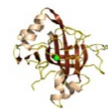

50ns

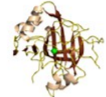

$60 \mathrm{~ns}$

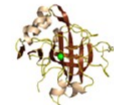

70ns

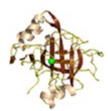

80ns

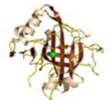

90ns

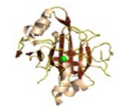

$100 \mathrm{~ns}$
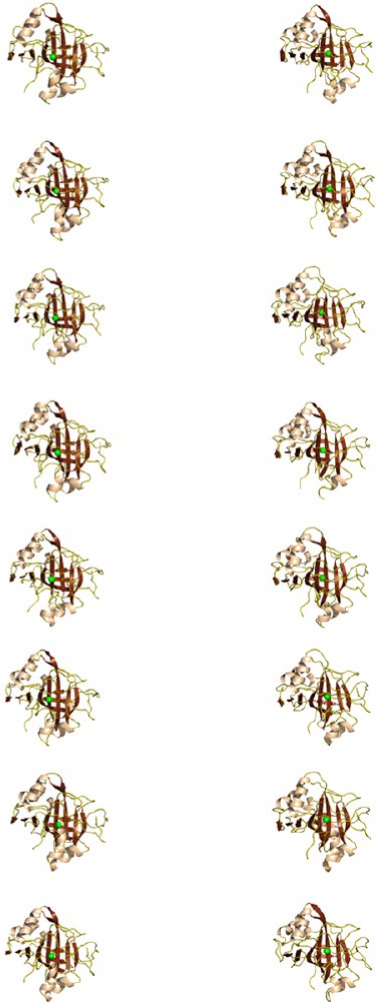
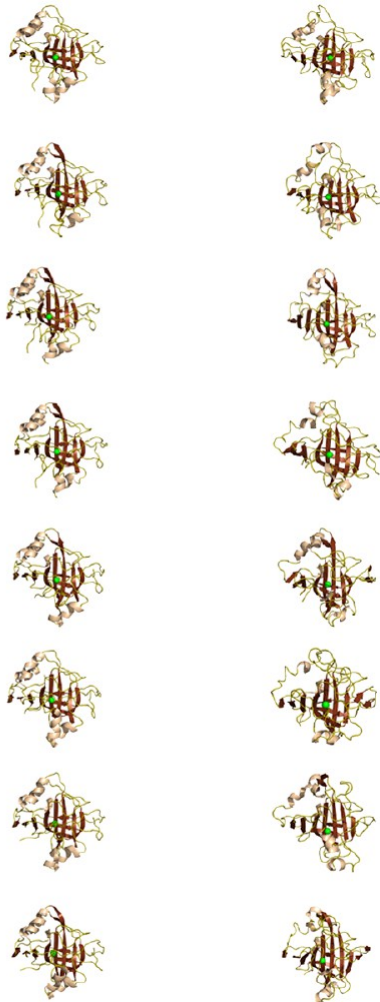

Figure 5. Unfolding pathway of (a) $\mathrm{Ng} \alpha$-CA, (b) Ssp $\alpha$-CA, and (c) mutant $\mathrm{Ng} \alpha$-CA. The study of unfolding pathway describes how a protein unwraps from its fully folded form. (a) $\mathrm{Ng} \alpha$-CA: presented in red and yellow; shows rapid loss in its secondary structure contents along its unfolding pathway, mostly at all different temperatures. (b) Ssp $\alpha$-CA: in different shades of blue; no significant loss observed at the initial temperature, but with an increase in temperature, shortening of the $\alpha 1$ and $\alpha 2$ helices has been observed at higher temperatures but later reappear with greater stability. (c) mutant $\mathrm{Ng} \alpha$-CA: presented in brown shades; follows a pathway more similar to the thermophilic protein, secondary structure contents are mostly maintained in compact form during all of the temperature simulations.

indicates that they have less unwrapping of their hydrophobic core region compared to the mesophilic protein. Thus, thermophilic and mutant proteins make fewer contacts with the outer solvent molecule with increasing temperature and maintain their higher stability (Table S1).

Unfolding Pathway. Analysis of the unfolding pathway of a protein predicts the pattern in which it unwraps from its native fully folded form to a completely unfolded state. Different protein conformations obtained from successive time scales throughout the MD simulation trajectory present specific stable and unstable domains in the protein structure. Different secondary structure contents, which stabilize protein's threedimensional (3D) conformations, can also be determined by this method. In this study, the detection of unfolding pathway suggests that the induced mutations in mesophilic $\alpha$-CA have a stabilizing influence on their corresponding secondary structure elements, which in turn contribute to the overall rigidity of the conformation (Figure 5). In short, we can look through a protein at the intramolecular level to find important interactions responsible for maintaining its stability during its proper folding. Unfolding pathway of all three (mesophilic, thermophilic and mutant) $\alpha$-CAs were studied according to successive time scales of increased temperature through their respective $\mathrm{MD}$ simulation trajectory.

Mesophilic $\alpha$-CA shows significant loss in its secondary structure contents along its unfolding pathway, mostly at all different temperatures. The $\alpha 4$ helix gradually decreases in size for the $300 \mathrm{~K}$ temperature simulation and is eliminated from the 20 to $80 \mathrm{~ns}$ time scale. This is probably caused by a certain increase in RMSF values of the residues Ala159-Leu162 in this region. Moreover, the $\mathrm{N}$-terminus of the largest $\beta$-sheet in the core hydrophobic twisted $\beta$-sheet region becomes shorter at 50 ns and onward during the $300 \mathrm{~K}$ temperature simulation. This $\mathrm{N}$-terminal region of the $\beta$-sheet in mesophilic $\alpha$-CA shows visible loss of its contents also at $10,30,40,80$, and 100 ns time scale of the $350 \mathrm{~K}$ temperature simulation. This extended fragment of core $\beta$-sheet is so unstable that it turns into a loop at the $30-100 \mathrm{~ns}$ time scale at $400 \mathrm{~K}$. At higher temperatures like $500 \mathrm{~K}$, no trace is found for this region between the time scale of 40 and 100 ns. The residue, Arg84, at the tip of the N-terminus of the above-mentioned $\beta$-sheet has a salt bridge interaction with Asp116 of its next $\beta$-sheet. This salt bridge becomes distorted between those time scales at $500 \mathrm{~K}$, causing the deformation of the $\beta$-sheet part. The $\mathrm{N}$-terminus of the $\alpha 3$ helix disappears and transforms into a loop in mesophilic $\alpha$-CA at $50-100 \mathrm{~ns}$ at $350 \mathrm{~K}$. This part of the $\alpha 3$ helix also disappears at 40 and $80 \mathrm{~ns}$ at $500 \mathrm{~K}$. Arg136 of $\alpha 3$ forms a salt bridge with Asp194 from $\beta 11$ at the beginning time scale of the $350 \mathrm{~K}$ simulation. This salt bridge breaks up between 50 and $100 \mathrm{~ns}$ at $350 \mathrm{~K}$ and 40 and $80 \mathrm{~ns}$ at $500 \mathrm{~K}$, causing the disappearance of both $\alpha 3$ and $\beta 11$. Both $\alpha 1$ and $\alpha 2$ helices disappear at 40 and 50 ns of the $400 \mathrm{~K}$ temperature simulation in mesophilic $\alpha$-CA and transform into a loop. The $\alpha 1$ helix is shown to reappear after 50 ns and exist till the end of the $400 \mathrm{~K}$ simulation. Lys 25 of $\alpha 1$ has a salt bridge interaction with Glu12 from the N-terminus loop of the protein. This salt bridge remains stable up to the $1-30 \mathrm{~ns}$ time scale of the $400 \mathrm{~K}$ simulation but after that, the salt bridge breaks down, resulting in the deformation of $\alpha 1$. Lys37 of $\alpha 2$ 
makes two salt bridges with Asp35 from the adjacent $\mathrm{N}$ terminus loop. These salt bridges remain stable up to the 1-30 ns time scale of the $400 \mathrm{~K}$ simulation. After that, the amine side chain of Lys37 moves toward a direction in which the salt bridges deform and $\alpha 2$ transforms into a loop. Between the time range of 20 and $60 \mathrm{~ns}$ of the $500 \mathrm{~K}$ simulation, a short $3^{10}$ helix appears at the $\mathrm{C}$-terminus of mesophilic $\alpha$-CA. Another $3^{10}$ helix appears adjacent to the previously mentioned $3^{10}$ helix at the end of the $500 \mathrm{~K}$ simulation. Frequent formation of such $3^{10}$ helices indicates weak interatomic interactions between the backbone residues at different local regions of mesophilic $\alpha$-CA, leading to the massive loss of secondary structure contents. All of the $\alpha$-helices gradually decrease in size and finally disappear at $70 \mathrm{~ns}$ at $500 \mathrm{~K}$. The $\beta$-sheets in the core of the twisted hydrophobic region also become very short in size, imparting structural instability to mesophilic $\alpha$-CA at $500 \mathrm{~K}$.

For thermophilic $\alpha$-CA, no significant loss or deviation of the secondary structure content from the initial conformation has been noticed. All of the $\beta$-sheets, especially the largest sheet in the central region of the hydrophobic twisted $\beta$-sheet region, remain structurally intact and stable all along the temperature simulations. A $3^{10}$ helix in the structure of thermophilic $\alpha$-CA frequently appears at $10,50,70$, and $100 \mathrm{~ns}$ time scale of the 300 $\mathrm{K}$ simulation. The salt bridges between Lys37 and Asp35 remain stable at those time scale of the $300 \mathrm{~K}$ simulation, which might be the cause of the repetitive appearance of this $3^{10}$ helix. Shortening of the N-terminal of $\alpha 1$ and $\alpha 2$ helices has been observed at 350 and $400 \mathrm{~K}$, but later these helices, especially $\alpha 1$, reappear with greater stability and remain intact for the rest of the simulations, even at the end of the $500 \mathrm{~K}$ temperature simulation. The stabilization of both $\alpha 1$ and $\alpha 2$ helices is mainly caused by the formation of salt bridges between Gln 16 of $\alpha 1$ and Lys 25 of $\alpha 2$.

In the case of mutant $\alpha$-CA, most of its secondary structure contents are maintained in a compact form for an extended time scale during all of the temperature simulations. There are no visible changes or significant loss in its secondary structure up to $80 \mathrm{~ns}$ at $300 \mathrm{~K}$. Specifically small structural fluctuation has been observed in the core twisted $\beta$-sheet region and the surface $\beta-8$ region. At $90 \mathrm{~ns}$ of the $300 \mathrm{~K}$ simulation, the $\mathrm{N}$-terminus of the largest $\beta$-sheet in the central hydrophobic core becomes reduced in size. The reduced part of this $\beta$-sheet reappears at $100 \mathrm{~ns}$ at the same temperature. The $\beta 8$ sheet of mutant $\alpha$-CA disappears at $20 \mathrm{~ns}$ in the $300 \mathrm{~K}$ simulation. The reduction of the $\mathrm{N}$ terminus of the largest $\beta$-sheet occurs again at 10,20,50, and 80 ns of the $350 \mathrm{~K}$ temperature simulation. But this part remained fully compact for the rest of the time scale at $350 \mathrm{~K}$. At $400 \mathrm{~K}$, this part of the largest core $\beta$-sheet reduces at 30,80 , and $90 \mathrm{~ns}$. At $500 \mathrm{~K}$, the $\mathrm{N}$-terminus of the $\beta$-sheet remains obsolete from 10 to $40 \mathrm{~ns}$. But after that time scale, this $\beta$-sheet remains intact in full length for the rest of the simulation time at $500 \mathrm{~K}$. The stability and reappearance of the core $\beta$-sheet in all of the abovementioned cases are mainly because of the existence of a strong salt bridge between Arg104 and Glu129. Interestingly, at the end of the simulation at $500 \mathrm{~K}$, an extra $\beta$-sheet is formed. The appearance of the small fragment of this $\beta$-sheet might be due to the formation of an adjacent $3^{10}$ helix. Asp194 of the small $\beta$ sheet fragment has a salt bridge interaction with $\operatorname{Arg} 136$ of the $3^{10}$ helix. On the other hand, the $3^{10}$ helix is formed due to the generation of a salt bridge between the mutant residue Glu139 and Arg136. The contributions from both this $\beta$-sheet and $3^{10}$ helix probably have some impact in retaining the other secondary structure of the mutant $\alpha$-CA, mostly intact at higher temperatures.

The protein secondary structure loses its integrity with increasing temperature. Increasing temperature also results in a high rate of dynamism in the structure. This leads to the possibility of formation of newer bonds, which is not possible at normal temperature. If two amino acids have side chains far apart while forming some interaction, then with increasing temperature, the kinetic energy increases and the side chains come together. That would lead to the formation of some stronger bonds, which is not possible at lower temperatures.

Comparative unfolding pathway depicts that $\mathrm{Ng} \alpha$-CA lost most of its secondary structure significantly from 70 to $100 \mathrm{~ns}$ at $500 \mathrm{~K}$. Notably, it can be found that helical contents are totally absent at the $70 \mathrm{~ns}$ time scale of the $500 \mathrm{~K}$ simulation in $\mathrm{Ng} \alpha$ $\mathrm{CA}$, and all of them transform into extended and flexible loops. On the other hand, both Ssp $\alpha$-CA and mutant $\mathrm{Ng} \alpha$-CA retain all their secondary contents at those high temperatures. Moreover, we have also reported that, during the time scale of 70,80 , and $100 \mathrm{~ns}$ of the $500 \mathrm{~K}$ temperature simulation, Ssp $\alpha$ $\mathrm{CA}$ and $\mathrm{Ng} \alpha$-CA show some small $\beta$-plated sheets on their surface, which seem to be responsible for their higher thermostability.

The energy compensation for the formation of such secondary structures with increasing temperature has already been discussed in the section of FEL. A protein has to cross a high-energy barrier for the deformation of those types of temporarily stable secondary structures. In our study, for thermophilic Ssp $\alpha$-CA and mutant $\operatorname{Ng} \alpha$-CA, the frequency of occurrence of such structures is more than that in its mesophilic counterpart, which make them more thermostable.

Constraint Network Analysis (CNA). CNA is a graphtheory-based rigidity analysis approach that determines global and local flexibility and rigidity characteristics of any protein from the trajectory of thermal unfolding simulations. By this method, relative differences between a structurally weak and a stable region of a protein can be detected with respect to thermal stability. We have used this method to predict the thermostability of proteins and to identify structural weak spots, that is, residues that upon mutation would improve a protein's thermostability. In this approach, a protein is modeled as a constraint network where atoms are connected by sets of bars representing different covalent and noncovalent interactions. A rigidity analysis performed on this network results in the decomposition of the protein into rigid parts and flexible links. Different noncovalent interactions (salt bridges and hydrogen bonds) remain involved in maintaining the temperaturedependent structural stability of a protein. By analyzing a series of networks of such a protein and determining the involvement of those noncovalent interactions, we are able to correlate the stability retention or the rigidity loss with a thermal unfolding study. Throughout the temperature gradient MD simulation study, we have that the rigid network becomes almost flexible in mesophilic $\alpha$-CA. Comparatively, we have observed that both thermophilic and mutant $\alpha$-CA are prone to retain most of their interaction networks even at a high temperature. These phase transitions in all of the $\alpha$-CA have been related to the thermodynamics of structural compactness provided by FEL.

Mutant residues Arg44 and Arg168 form additional salt bridge interactions with Glu226 in the newly engineered $\alpha$-CA. These additional salt bridges are supposed to be responsible for the formation of a greater and rigid interaction network adjacent to those newly formed salt bridges in the mutant $\alpha$-CA. This 
(a)

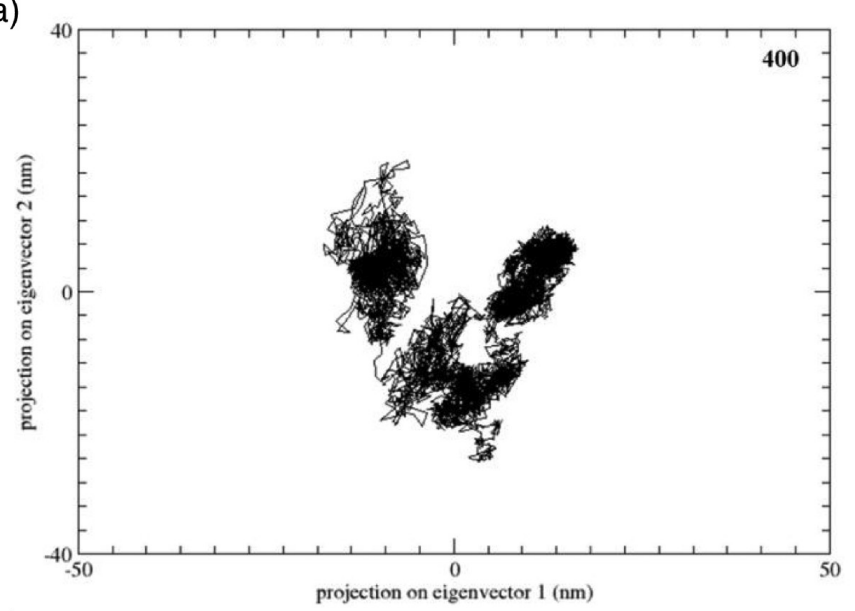

(b)
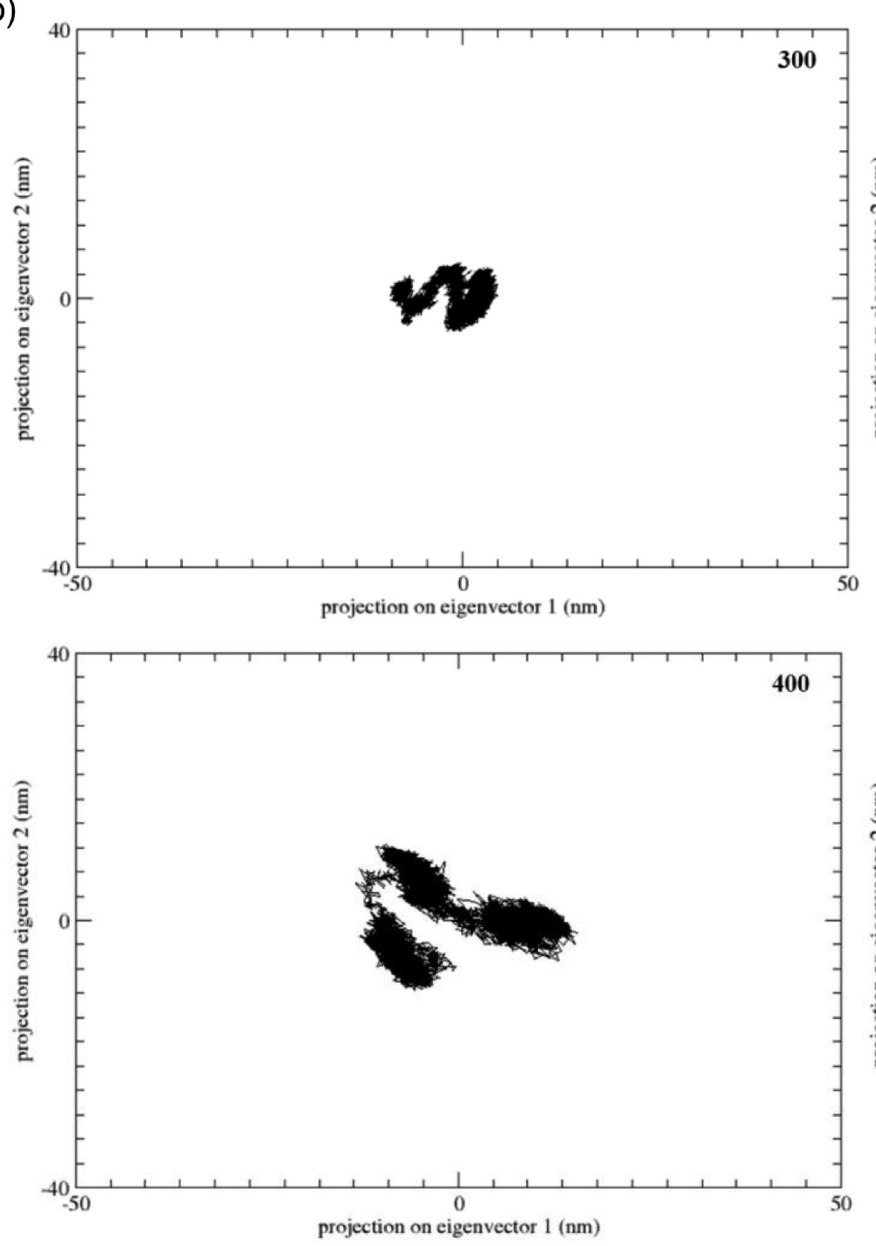

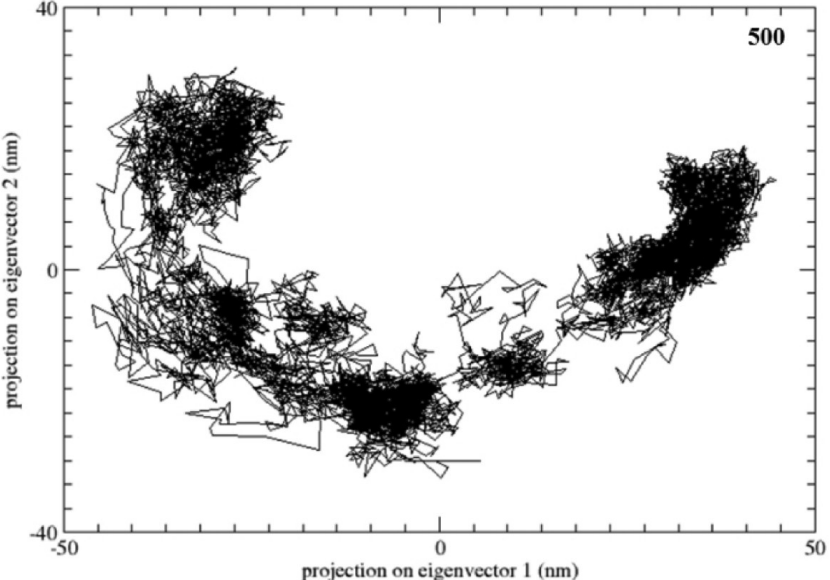

projection on eigenvector $1(\mathrm{~nm})$
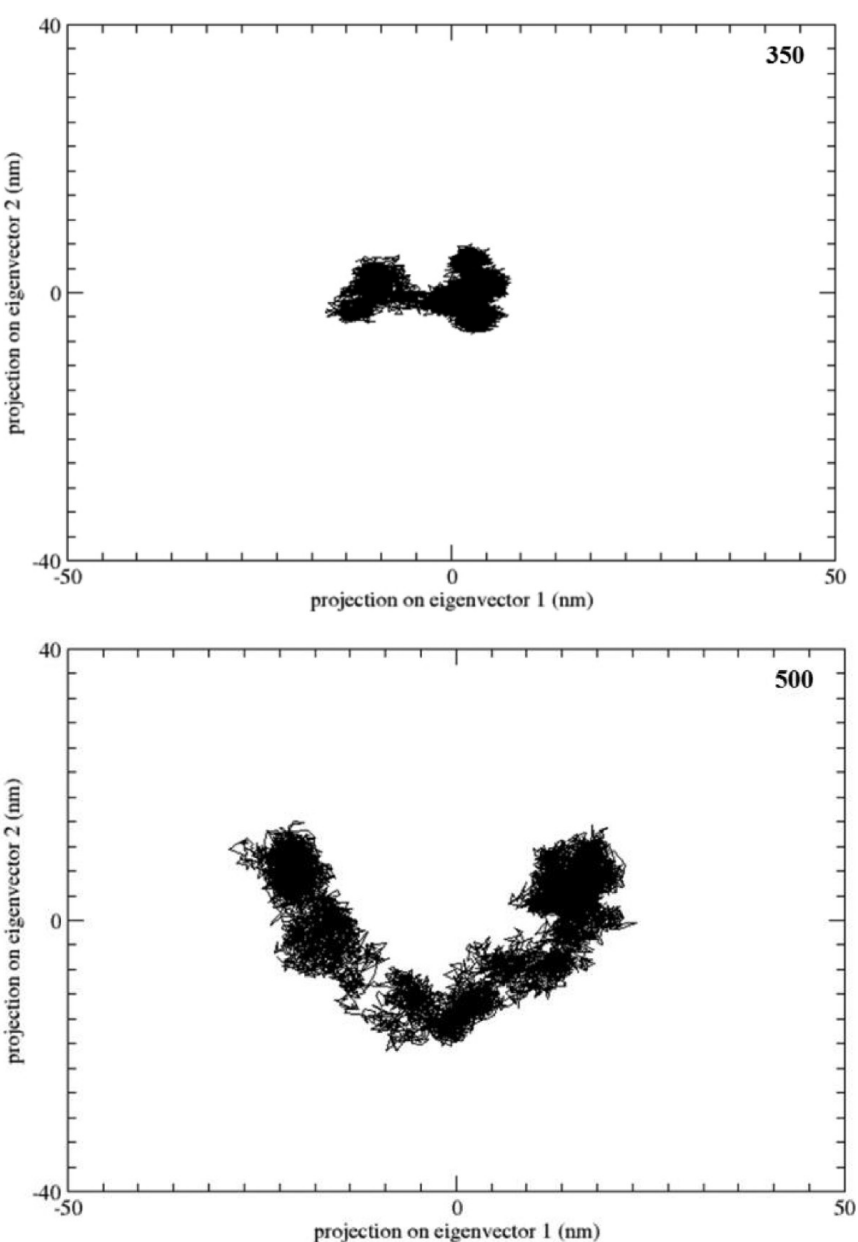

Figure 6. continued 
(c)
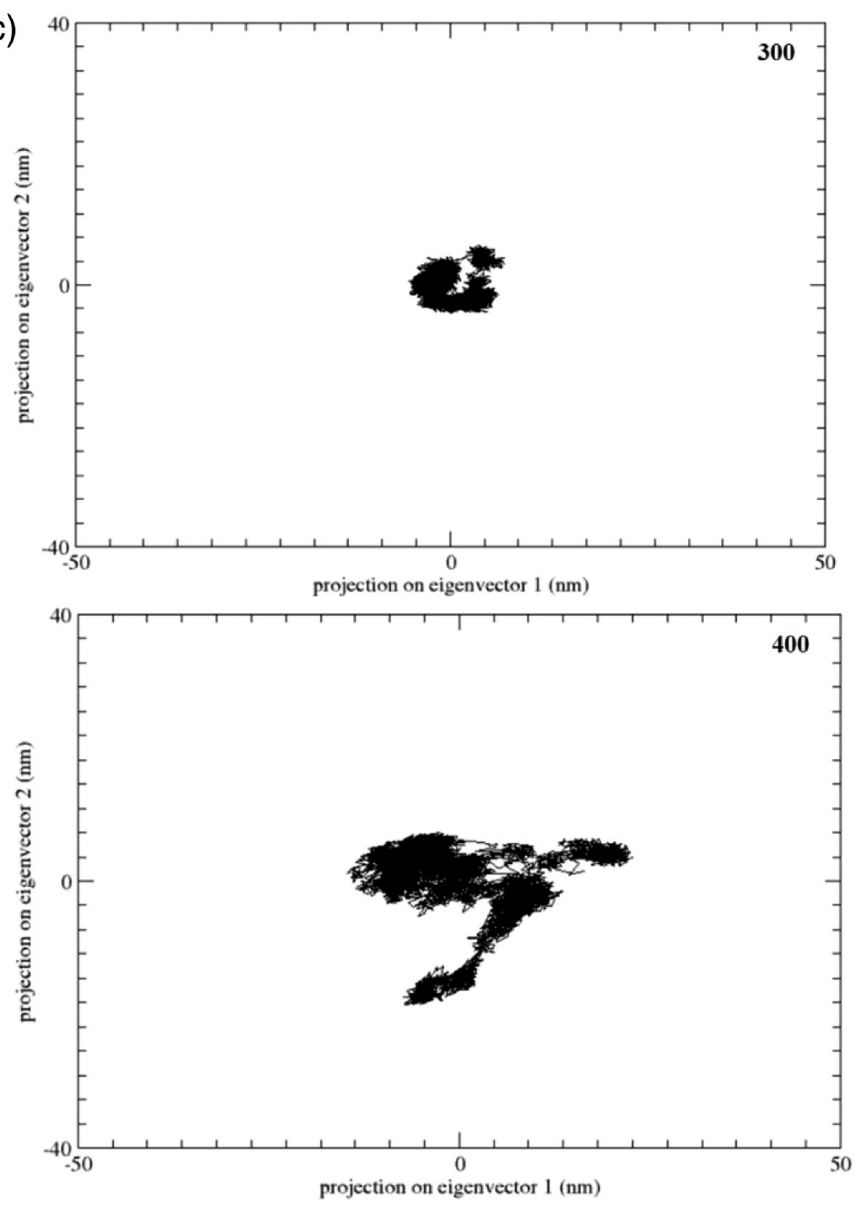
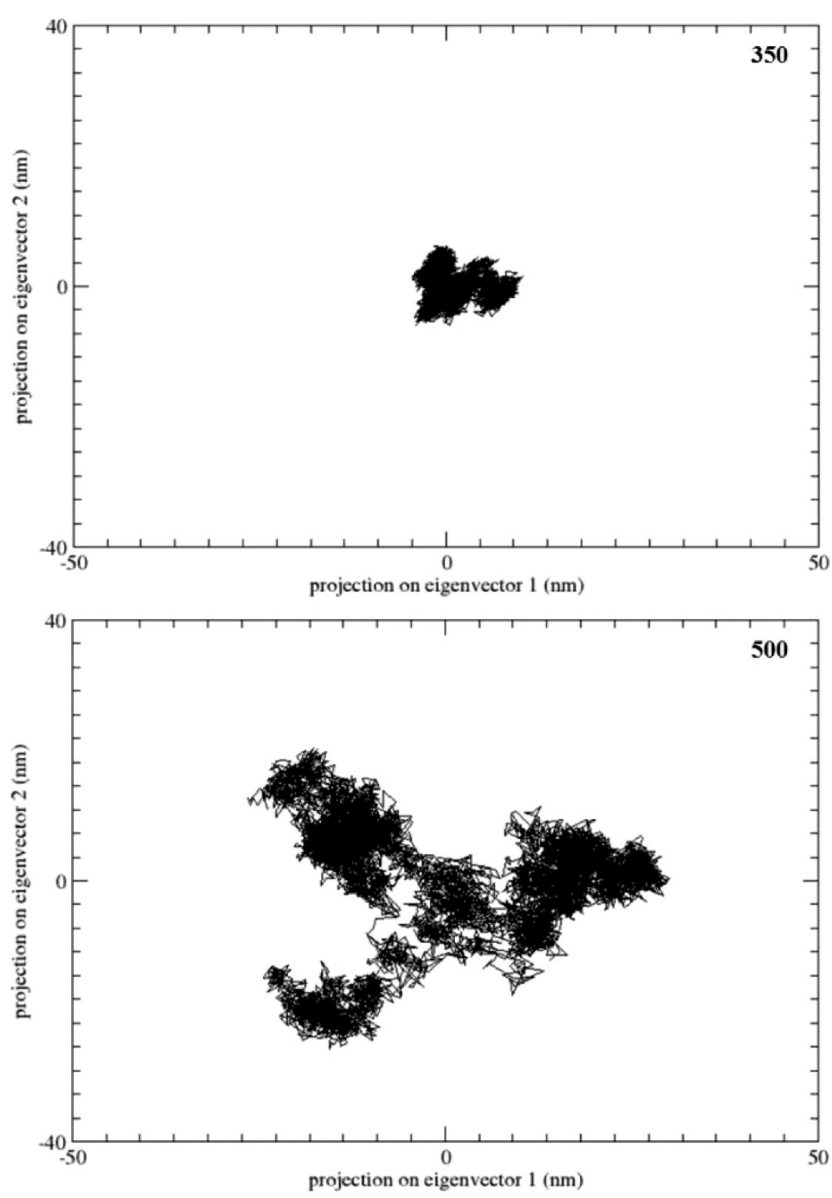

Figure 6. PCA for a. $\mathrm{Ng} \alpha$-CA, b. Ssp $\alpha$-CA, and c. mutant $\mathrm{Ng} \alpha$-CA. PCA determines the movement of protein backbone during the MD simulation, which is extremely critical to understand protein unfolding. a. $\mathrm{Ng} \alpha$-CA: shows rapid increase in backbone movement with increasing temperature, $\mathrm{b}$. Ssp $\alpha$-CA: relatively less spreading throughout the simulations at all temperatures and c. mutant $\mathrm{Ng} \alpha$-CA: shows movement quite similar to Ssp-CA but increases significantly for the $500 \mathrm{~K}$ simulation.

type of rigid interaction network is the main reason for acquiring increased thermal stability in both thermophilic and mutant $\alpha$ CA.

PCA. PCA is used to determine the movement of the protein backbone during the MD simulation. The majority of the protein backbone motion is determined by the first two principal components. The protein backbone motion is plotted in two-dimensional covariance matrices as a function of principal component 1 (PC1) and principal component 2 (PC2).

Both eigenvalues (PC1 and PC2) of mesophilic $\mathrm{Ng} \alpha$-CA fluctuate between -50 and $+50 \AA$ at $300 \mathrm{~K}$, whereas PC1 of Ssp $\alpha$-CA ranges between -100 and +50 and PC2 from -50 to +50 $\AA$. For the mutant, both $\mathrm{PC} 1$ and $\mathrm{PC} 2$ values range between -50 and $+100 \AA$. The range of both PC1 and PC2 of mesophilic $\alpha$-CA increases compared to thermophilic $\alpha$-CA, which is $(-150,+150)$ at $350 \mathrm{~K}$. In the case of thermophilic $\alpha$-CA, the $\mathrm{PC} 1$ value ranges between -200 and $+100 \AA$, and the PC2 value remains in the range -100 to $+100 \AA$. For mutant $\alpha$-CA, the PC1 and PC2 values range between -50 to $+100 \AA$ and -50 to $+50 \AA$, respectively. Visible changes in backbone motion have been reported in the case of $\mathrm{Ng} \alpha$-CA at $400 \mathrm{~K}$, in which the PC1 value fluctuates from -200 to +200 and the PC2 value from -250 to +200 . On the other hand, the PC1 and PC2 values of thermophilic $\alpha$-CA range within a small scale, $-150,+150 \AA$ (PC1) and $-100,+100 \AA$ (PC2). For the mutant, the PC1 value ranges between -150 and $+250 \AA$, and PC2 ranges between -200 and $+75 \AA$ A. Similarly, at $500 \mathrm{~K}$, larger flexibility along both eigenvectors (PC1: $-35,+45 \AA$; PC2: $-35,+30 \AA$ ) is shown by $\mathrm{Ng} \alpha$-CA. In the case of thermophilic $\alpha$-CA, the fluctuations of the protein backbone along with the eigenvectors are less $(\mathrm{PC} 1$ : $-300,+250 \AA$ and PC2: $-200,+150 \AA)$. In mutant $\alpha$-CA, PC1 ranges between -270 and $+300 \AA$, and PC2 ranges between -250 and $+200 \AA$.

Essential Dynamics (ED). ED analyses during PCA have been performed to monitor the overall concerted motion of all of the three proteins, mesophilic, thermophilic, and mutant $\alpha$ $\mathrm{CA}$, at different temperatures. To examine the efficiency of the sampling of conformational space, we have calculated the cosine content of the first two principal components (PC1 and PC2) at all of the temperatures.

In ED calculations, we have calculated the degree of backbone overlap of an individual protein at different temperatures. As mesophilic $\alpha$-CA is comparatively unstable compared to thermophilic and mutant ones, it shows less percentage of overlap between the backbones of different conformations at various temperatures. Thermophilic and mutant $\alpha$-CA show comparatively larger number of conformations with their backbone overlap. This pattern of ED reveals that thermophilic and mutant $\alpha$-CA have smaller fluctuations at different local domains compared to mesophilic $\alpha$-CA. In this analysis, it is also reported that the comparatively stable thermophilic and mutant 
(a)
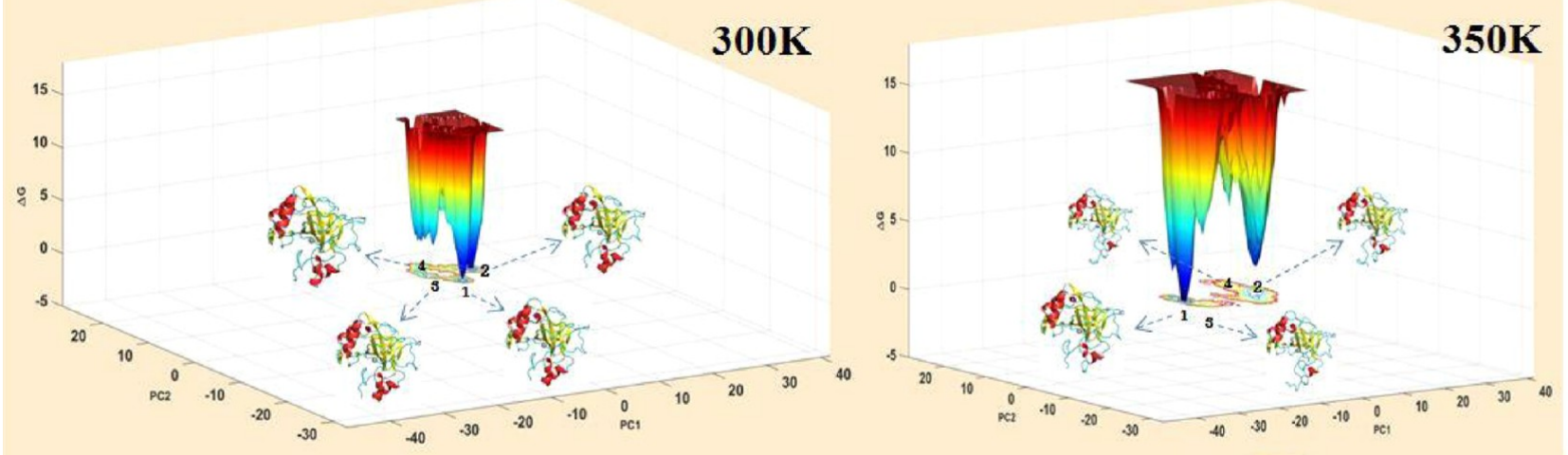

350K
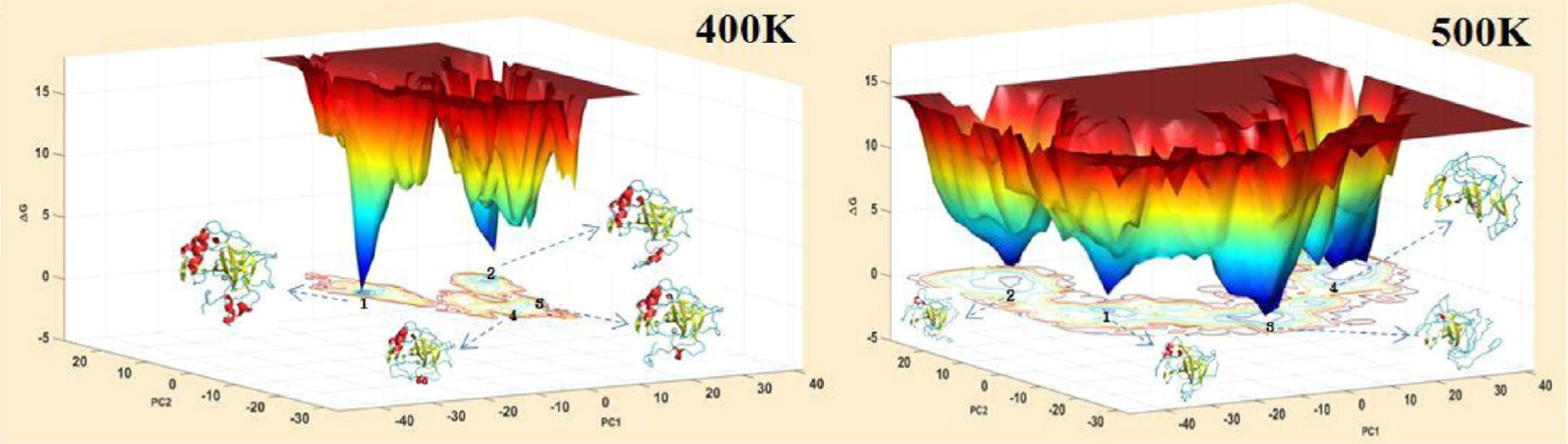

(b)

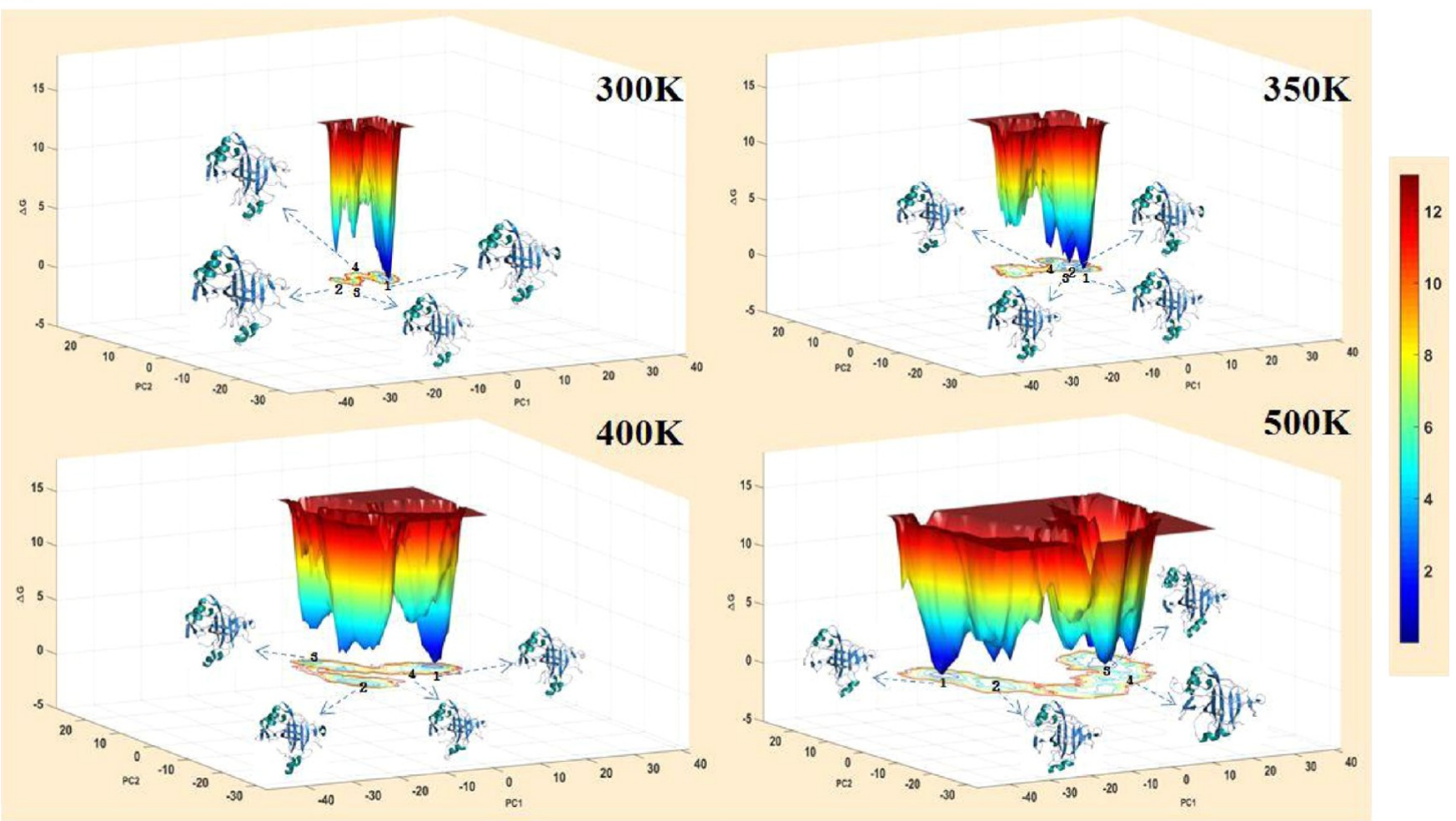

Figure 7. continued 
(c)

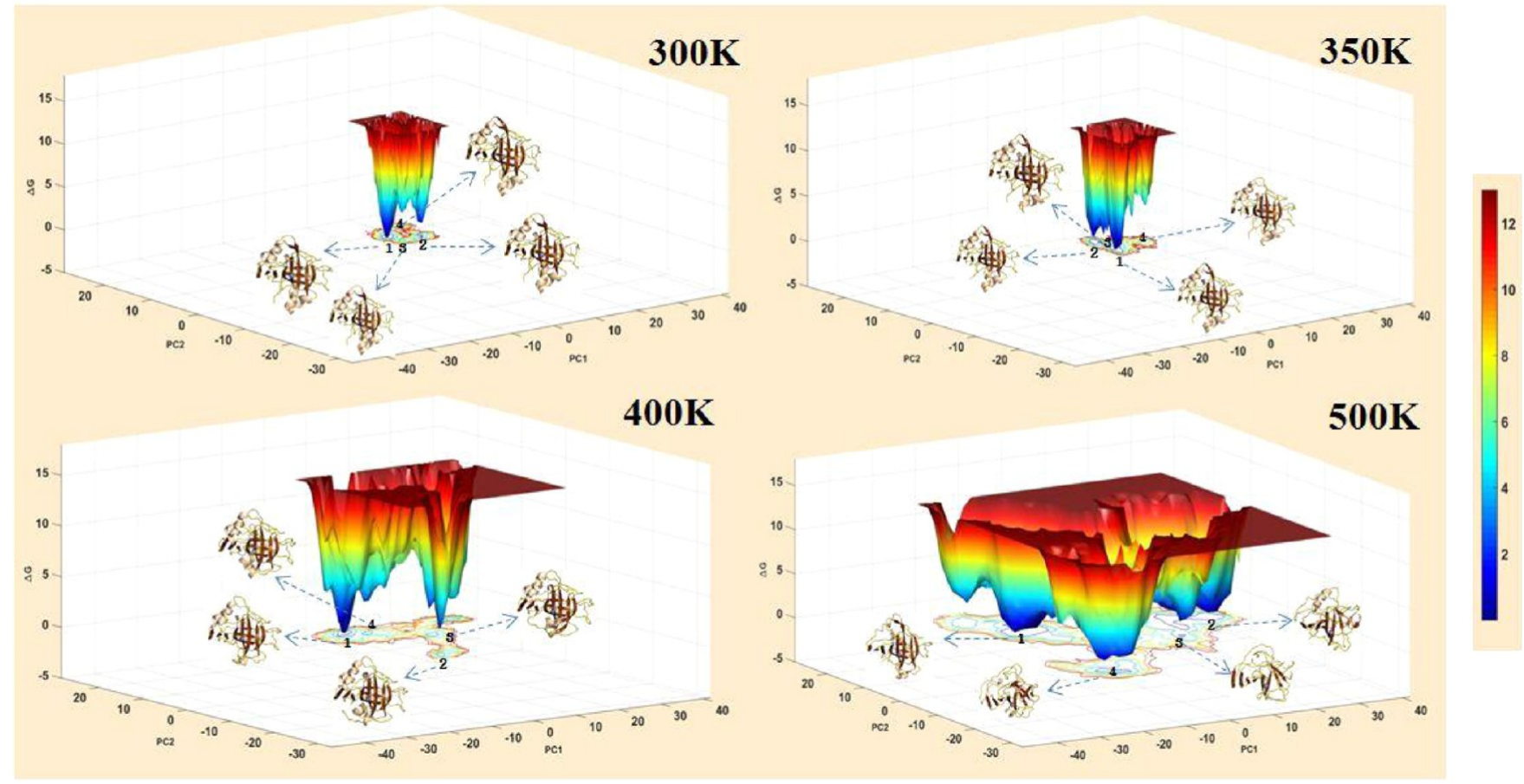

Figure 7. FEL of a. $\mathrm{Ng} \alpha$-CA, b. Ssp $\alpha$-CA, and c. mutant $\mathrm{Ng} \alpha$-CA. Coloring pattern defines the energy distribution; blue and red defines the conformational space of a protein with minimum energy (stable state) and maximum energy (unstable state), respectively. Intermediate color patterns highlight the other transient local energy states. Energy landscape follows similar pattern like PCA; i.e., the more spread the landscape is, the more unfolded is the protein.

$\alpha$-CA proteins have their backbone motion mostly in the same direction for different conformations throughout the trajectories of temperature gradient, whereas the relatively less stable mesophilic $\alpha$-CA shows residual backbone motion mostly in the opposite two directions for different conformations throughout the time scale of the temperature gradient MD simulation trajectory. The width of the ribbon in all of the three types of $\alpha$ CA proteins represents the degree of backbone motion. The ribbon representation of the ED for all of these proteins shows different amplitudes of motion of a specific region of those proteins. From our study, it is clear that mesophilic $\alpha$-CA has visible expansion and a larger dimension of the ribbon compared with thermophilic and mutant $\alpha$-CA. The region of the largest $\beta$ sheet in the core hydrophobic $\beta$-twisted region and the surface $\beta 8$ region in mesophilic $\alpha$-CA shows a greater dispersion in backbone motion. Compared to that in this scenario, thermophilic and mutant $\alpha$-CA show less amplitude of motion in those regions. This observation is also supported by the finding of the unfolding pathway.

From the comparative ED and PCA, we are able to correlate the role of stabilizing and destabilizing salt bridge-forming residues in maintaining thermal stability. There are some destabilizing salt bridge-forming residue pairs in mesophilic $\mathrm{Ng}$ $\alpha$-CA: Lys102-Arg104, Arg136-Lys165, Lys165-arg166, Arg166-Lys168, and Lys132-Arg136, which are mainly responsible for the larger domain-specific fluctuation compared to the thermophilic one. The corresponding residue pairs in the case of thermophilic $\alpha$-CA are Glu99-Lys101, Glu133-Lys162, Lys162-Asp163, Asp163-Arg165, and Lys99-Glu133. Among them Glu99, Glu133, Asp163, and Arg165 are shown to form stabilizing salt bridges and assumed to have an impact on the small fluctuations of backbone atoms along the two principal eigenvectors. In the case of mutant $\alpha$-CA, stabilizing salt bridge- forming residues Glu139 and Arg168 are responsible for the lower backbone atom fluctuation, as in thermophilic $\alpha$-CA.

The above-mentioned comparative PCA values of mesophilic and thermophilic $\alpha$-CA reveal that thermophilic and mutant Ssp $\alpha$-CA have less backbone motion than their mesophilic counterpart. Less backbone motion and atomic degree of motion indicate rigid and stable conformations of thermophilic and mutant $\alpha$-CA at higher temperatures (Figures 6 and S7).

FEL. The corresponding FEL as a function of the principal components describes the energy distribution of a proteinfolding pathway. It depicts the stability of protein in terms of the Gibbs free energy and analyzes different conformational states as a function of energy for each residue involved.

$$
\Delta G=\sum-K T_{\mathrm{B}} \ln \left(P_{\mathrm{A}}-P_{\mathrm{B}}\right)
$$

Here, $\Delta G$ defines the Gibbs Free energy and is a function of $K$ and $T_{B}$, which are the equilibrium constant and gas constant, respectively, $P_{\mathrm{A}}$ and $P_{\mathrm{B}}$ are the probabilities of the occurrence of the A conformation and $\mathrm{B}$ conformation, respectively, of a protein in its dynamics pathway .

We have analyzed FEL from the MD simulation trajectories of the simulated systems of the wild-type mesophilic, thermophilic, and mutant $\alpha$-CA. Interactive 3D plots have been generated by using the Gibbs free energy as a function of two eigenvectors (PC1 and PC2), obtained from the principal component analysis. The principal component projected covariance matrix has been highlighted with a contour map, showing different coloring patterns at the bottom of each FEL plot. Each coloring pattern defines a range of energy distribution in which the protein shows its different configurations. Blue and red define the conformational spaces of a protein with minimum energy (stable state) and maximum energy (unstable state), respec- 
tively. Intermediate color patterns highlight the other transient local energy states. In the case of $\alpha$-CA, we get different intermediate states for different temperature simulations. By detecting the intermediate states and the energy profile of residues corresponding to each state, we can detect the residues that are important for stabilizing those intermediate states and regulating the activity. In combination, FEL and conformation path sampling methods analyzed from MD simulation trajectories help us locate different important states of $\alpha$-CAs during their folding pathways, which have biological significance in maintaining thermal stability. A comparative analysis of FEL of thermophilic, mesophilic, and mutant $\alpha$-CA shows greater stability for thermophilic and mutant $\alpha$-CA.

A comparative analysis of FEL of different temperatures shows that the expansion of the energy funnel opening in $\mathrm{Ng} \alpha$ $\mathrm{CA}$ is more than that of $\operatorname{Ssp} \alpha$-CA and the mutant one. $\mathrm{Ng} \alpha$-CA has a larger sampling for the two principal component values than that of Ssp $\alpha$-CA. Significant difference in the expansion of the FEL opening can be observed at a temperature of $350 \mathrm{~K}$. At high temperatures, that is, $500 \mathrm{~K}$, the differences in the principal component values become much higher between the mesophilic and thermophilic $\alpha$-CA. The number of intermediate states in $\mathrm{Ng} \alpha$-CA is more than that in Ssp $\alpha$-CA with multiple lower free-energy barriers in the case of $\mathrm{Ng} \alpha$-CA. Because of this, the surface of FEL for $\mathrm{Ng} \alpha$-CA is more rugged than that of Ssp $\alpha$ $\mathrm{CA}$. The higher number of free-energy barriers in the $\mathrm{Ng} \alpha$-CA FEL than that in $\operatorname{Ssp} \alpha$-CA and mutant $\alpha$-CA indicates that each local minimum of the landscape contains a stable conformation. Because of the presence of a large number of intermediate conformations, $\mathrm{Ng} \alpha$-CA takes longer time scales to fold into its native state. In addition, the global minimum of free energy of $\mathrm{Ng} \alpha$-CA is higher than that of the Ssp $\alpha$-CA and mutant $\alpha$-CA FEL. Another cause of the slow folding of the mesophilic $\mathrm{Ng} \alpha$ CA protein is that this protein has to cross more number of larger energy barriers to transform from one intermediate conformation to the other. The RMSD and $R_{\mathrm{g}}$ value differences are significantly higher between the intermediate states of $\mathrm{Ng} \alpha$ CA compared to those of Ssp $\alpha$-CA and mutant $\alpha$-CA. Because of this large number of intermediate states between any two global minima in the $\mathrm{Ng} \alpha$-CA protein, it has to transverse a large energy barrier for proceeding along its folding pathway to achieve the native state. Analyzing different conformations of mesophilic $\mathrm{Ng} \alpha$-CA from the FEL plots of increasing temperature gradient compared to thermophilic Ssp $\alpha$-CA and mutant $\alpha$-CA, it is clear that mesophilic $\mathrm{Ng} \alpha$-CA is highly flexible and more unstable than its thermophilic counterpart and mutant $\alpha$-CA.

All of the FELs at different temperatures show a trend that the expansion of the opening of the landscape is much larger in the mesophilic protein than its thermophilic counterpart and the mutant one (Figure 7). The sampling of landscape becomes comparatively more with increasing temperature in the case of mesophilic protein. It is further evident as the mesophilic protein has more fluctuations in backbone motion and increased degree of freedom compared to others. Because of its greater unfolding rate and flexibility, the possibility of the occurrence of intermediate conformations is much more than other variants. The wild-type mesophilic $\alpha$-CA sampled wider regions on the FEL than thermophilic and mutant ones, significantly at 400 and $500 \mathrm{~K}$. From $350 \mathrm{~K}$ onward to $500 \mathrm{~K}$, the FELs of both thermophilic and mutant $\alpha$-CA show the presence of distinct basins separated by a relatively high free-energy barrier compared to the wild-type mesophilic $\alpha$-CA. At 350, 400, and
$500 \mathrm{~K}$, thermophilic and mutant $\alpha$-CA show a greater coverage of conformational space along the first two PCs compared to the wild-type mesophilic $\alpha$-CA. In contrast, the wild-type mesophilic $\alpha$-CA is found to sample overlapping regions of conformational space, wherein the conformations are largely clustered in regions along PC1 and PC2 due to the formation of weak hydrogen bonds and hydrophobic collapses. Mesophilic $\alpha$ CA shows large concerted motions in different parts of the trajectories, represented by the movements along PC1 and PC2 eigenvectors. In contrast, thermophilic and mutant $\alpha$-CA show restricted motions, significantly in the $\mathrm{N}$-terminal region $(\alpha$ helix, twisted $\beta$-sheets in the protein hydrophobic core, and loops) and in the surface loops of the protein. Mesophilic $\alpha$-CA possesses a higher free energy of unfolding than thermophilic and mutant $\alpha$-CA. For this reason, thermophilic and mutant $\alpha$ CA show more thermostability than mesophilic $\alpha$-CA.

We have also characterized different states and their freeenergy values. Different states of protein unfolding pathway, such as folded, partially unfolded, hydrophobic collapsed, and unfolded states, are labeled with 1, 2, 3, and 4 (major basins), respectively, in the energy contour map at the bottom of the FEL plot (Figure 7). Thermophilic and mutant $\alpha$-CA show the least conformational fluctuation and movement in native (folded states) or near-to-native basins, suggesting the existence of large free energy barriers between native and non-native states (partially unfolded states). In contrast, mesophilic $\alpha$-CA shows rapid transitions from native to non-native FEL basins, suggesting its increased tendency to sample conformationally distant non-native states at high temperatures. Notably, the wild-type mesophilic $\alpha$-CA shows a higher fluctuation than thermophilic and mutant $\alpha$-CA and follows a constricted transition pathway from native to non-native FEL basins (Figure 7).

Comparing the average RMSD values and analyzing the variation in hydrogen bonds and salt bridges between major FEL basins, it was evident that thermophilic and mutant $\alpha$-CA resist the breaking of hydrogen bonds and salt bridges and hence, remain close to the native conformations at high temperatures (Tables $\mathrm{S} 2-\mathrm{S} 4$ ).

$\mathrm{p} K_{\mathrm{a}}$ Calculation. From $\mathrm{p} K_{\mathrm{a}}$ calculations, we have found that Ssp $\alpha$-CA has a $K_{\mathrm{a}}$ value (6.9) near 7 at a $\mathrm{pH}$ of 8 , whereas mesophilic $\mathrm{Ng} \alpha$-CA has a comparatively lower $\mathrm{p} K_{\mathrm{a}}$ value of 6.7 at the same $\mathrm{pH}$. This result implicates that the histidine (His64 in Ssp $\alpha$-CA) remain in a more deprotonated state relative to mesophilic $\mathrm{Ng} \alpha$-CA His66. Thus, His64 from Ssp $\alpha$-CA is more capable of abstracting the proton from the water attached to the zinc ion. Therefore, the rate of nucleophilic attack on the carbon of $\mathrm{CO}_{2}$ by the deprotonated hydroxyl group $(\mathrm{Zn}-\mathrm{OH})$ is more in Ssp $\alpha$-CA. More interestingly, in the case of the newly designed mutant $\mathrm{Ng} \alpha$-CA, we have calculated the $\mathrm{p} K_{\mathrm{a}}$ value of His 66 to be 6.8 , higher than that of the wild-type histidine. From this, it can be assumed that mutant $\mathrm{Ng} \alpha$-CA comes up with more enzymatic activity than the wild-type $\mathrm{Ng} \alpha$-CA in addition to its thermal stability, as in thermophilic Ssp $\alpha$-CA.

Dynamics Study of Zn-HisND1 Involved in the Proton Shuttle. From the MD simulation trajectories, we have compared the conformations of the catalytic histidine residue (involved in the proton shuttle) and the $\mathrm{Zn}-\mathrm{HisND} 1$ distance for all of the three systems: $\operatorname{Ng} \alpha$-CA, $\operatorname{Ssp} \alpha$-CA, and mutant $\mathrm{Ng}$ $\alpha$-CA. Considering the HisND1-Zn distance of up to $8 \AA$ for the optimum catalytic activity of $\alpha$-CA, we have identified those "in" conformers that facilitate the proton shuttle. At $300 \mathrm{~K}$, we have reported two "in" conformers of the catalytic histidine each 
Table 2. Comparative HisND1-Zn Distances of Mesophilic Ng $\alpha$-CA, Thermophilic Ssp $\alpha$-CA and Mutant Ng $\alpha$-CA

\begin{tabular}{|c|c|c|c|c|c|c|c|c|c|c|c|c|}
\hline & \multicolumn{3}{|c|}{$300 \mathrm{~K}$} & \multicolumn{3}{|c|}{$350 \mathrm{~K}$} & \multicolumn{3}{|c|}{$400 \mathrm{~K}$} & \multicolumn{3}{|c|}{$500 \mathrm{~K}$} \\
\hline & meso & thermo & mutant & meso & thermo & mutant & meso & thermo & mutant & meso & thermo & mutant \\
\hline $10 \mathrm{~ns}$ & 9.9 & 9.3 & 11.7 & 7.6 & 9.7 & 14.3 & 8.3 & 9.8 & 13.0 & 12.6 & 6.8 & 6.3 \\
\hline $20 \mathrm{~ns}$ & 10.2 & 7.2 & 12.3 & 7.7 & 8.5 & 13.9 & 6.4 & 8.2 & 11.2 & 9.8 & 6.7 & 8.8 \\
\hline $30 \mathrm{~ns}$ & 11.1 & 11.2 & 11.3 & 8.0 & 12.3 & 13.4 & 10.2 & 10.2 & 10.6 & 10.6 & 14.4 & 18.5 \\
\hline $40 \mathrm{~ns}$ & 12.0 & 13.0 & 10.5 & 7.2 & 11.3 & 13.7 & 10.6 & 8.7 & 7.5 & 16.9 & 12.9 & 7.5 \\
\hline $50 \mathrm{~ns}$ & 7.4 & 11.4 & 10.5 & 7.3 & 8.4 & 13.2 & 7.9 & 4.5 & 8.1 & 6.9 & 10.7 & 10.4 \\
\hline $60 \mathrm{~ns}$ & 8.4 & 7.4 & 11.6 & 10.1 & 8.1 & 13.9 & 7.6 & 8.8 & 7.7 & 15.1 & 16.4 & 13.2 \\
\hline $70 \mathrm{~ns}$ & 8.2 & 9.2 & 11.3 & 7.9 & 12.4 & 12.9 & 7.8 & 4.2 & 8.4 & 7.8 & 17.4 & 13.9 \\
\hline $80 \mathrm{~ns}$ & 7.5 & 11.9 & 10.7 & 11.5 & 8.1 & 14.0 & 7.4 & 4.0 & 9.0 & 10.1 & 13.6 & 12.6 \\
\hline $90 \mathrm{~ns}$ & 8.5 & 10.5 & 11.2 & 6.7 & 7.4 & 13.0 & 9.4 & 11.2 & 9.2 & 14.7 & 20.9 & 10.6 \\
\hline $100 \mathrm{~ns}$ & 8.2 & 10.8 & 11.0 & 8.3 & 8.7 & 13.9 & 9.5 & 8.7 & 7.2 & 17.1 & 16.1 & 10.6 \\
\hline
\end{tabular}

${ }^{a}$ All distances are in Angstrom ( $)$. HisND1-Zn distances $\leq 8 \AA$ are in bold.
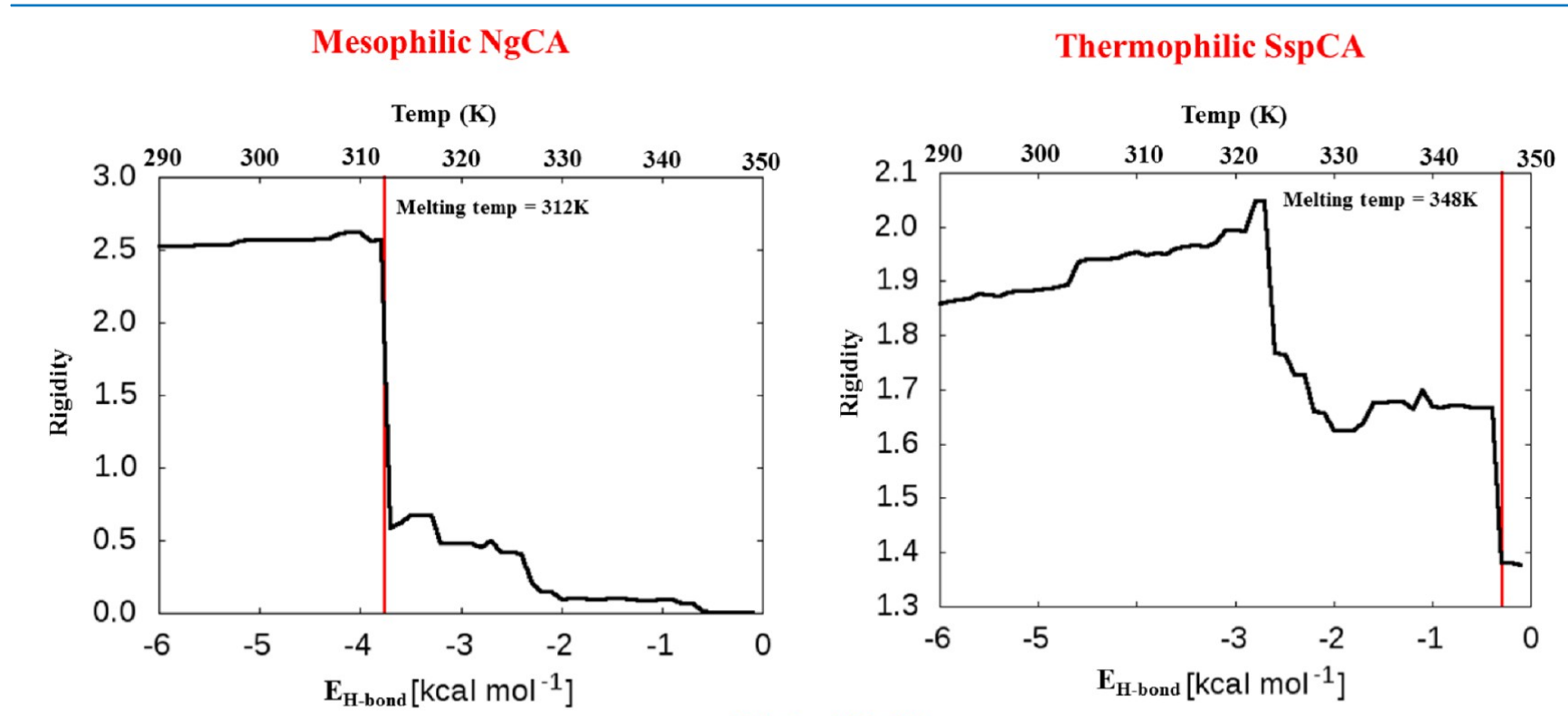

Mutant NgCA

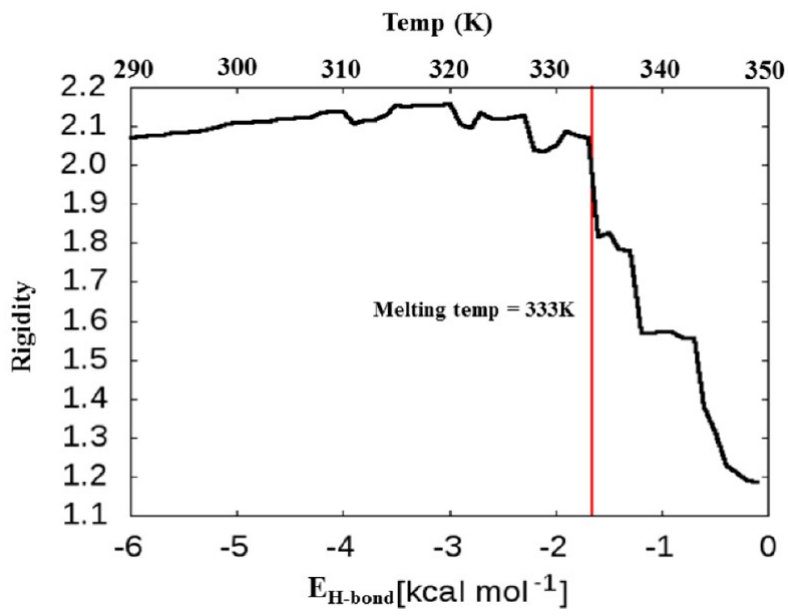

Figure 8. Comparative denaturation temperature $\left(T_{\mathrm{m}}\right)$ of mesophilic $\mathrm{Ng} \alpha$-CA, thermophilic Ssp $\alpha$-CA, and mutant $\mathrm{Ng} \alpha$-CA. Vertical red bar indicates $T_{\mathrm{m}}$ for each of the system.

for $\mathrm{Ng} \alpha$-CA $(50,80 \mathrm{~ns})$ and Ssp $\alpha$-CA (20, $60 \mathrm{~ns})$. The distances of HisND1-Zn for $\mathrm{Ng} \alpha$-CA for these two conformers are 7.4 and $7.5 \AA$, whereas in the case of Ssp $\alpha$ CA, these distances are 7.2 and $7.4 \AA$, respectively. At $350 \mathrm{~K}$, His66 of $\mathrm{Ng} \alpha$-CA shows a comparatively larger number of "in" conformations for time scales $10-50,70$, and 90 ns. The HisND1-Zn distances in $\mathrm{Ng} \alpha$-CA for those time scales at 350 $\mathrm{K}$ are $7.6,7.7,8.0,7.2,7.3,7.9$, and 6.7, respectively. At the same temperature, Ssp $\alpha$-CA shows an "in" conformer of His64 only at the $90 \mathrm{~ns}$ time scale, which has a HisND1-Zn distance of 7.4. 
At $400 \mathrm{~K}$, mesophilic $\mathrm{Ng} \alpha$-CA shows five "in" conformers of His66 within a HisND1-Zn distance of $8 \AA$ at the time scale of $20 \mathrm{~ns}$ and from 50 to $80 \mathrm{~ns}$. For thermophilic Ssp $\alpha$-CA, we have reported three "in" conformers of His64 at the 50, 70, and 80 ns time scale. In these three conformers, the distances between $\mathrm{Zn}$ and HisND1 are much less, which are 4.5, 4.2, and $4.0 \AA$, respectively. The comparative HisND1-Zn distance between those "in" conformers of catalytic histidine of $\mathrm{Ng} \alpha$-CA and Ssp $\alpha$-CA implies that less HisND1-Zn distance is more compatible for a fast proton transfer in the case of Ssp $\alpha$-CA to attain its maximum enzymatic activity even at temperatures as high as 400 $\mathrm{K}$. In the case of mutant $\mathrm{Ng} \alpha$-CA, three "in" conformers have been observed at $400 \mathrm{~K}$, which have HisND1-Zn distances of 7.5, 7.7, and 7.2 at 40,60 , and $100 \mathrm{~ns}$, respectively. At $500 \mathrm{~K}$, mesophilic $\mathrm{Ng} \alpha$-CA has two "in" conformers of His66 with HisND1-Zn distances of 6.9 and $7.8 \AA$ at 50 and $70 \mathrm{~ns}$, respectively. Even for thermophilic $\operatorname{Ssp} \alpha$-CA, there are two "in" conformers of His64 with HisND1-Zn distances of 6.8 and 6.7 $\AA$ at 10 and $20 \mathrm{~ns}$, respectively. At $500 \mathrm{~K}$, the mutant $\mathrm{Ng} \alpha$-CA shows two "in" conformers of its His66 with HisND1-Zn distances of 6.3 and $7.5 \AA$ at 20 and 40 ns, respectively. More interestingly, if we successively compare the HisND1-Zn distance of mutant $\mathrm{Ng} \alpha$-CA at 10 ns with the wild-type $\mathrm{Ng} \alpha$ CA HisND1-Zn distance at $50 \mathrm{~ns}$ and the same at $40 \mathrm{~ns}$ for mutant $\mathrm{Ng} \alpha$-CA and at $70 \mathrm{~ns}$ for wild-type $\mathrm{Ng} \alpha$-CA, then we can find that the distances are comparatively less for mutant $\mathrm{Ng}$ $\alpha$-CA (Table 2). In addition, for thermophilic Ssp $\alpha$-CA, the HisND1-Zn distances for the two "in" conformers of His64 are also less compared to those for mesophilic $\mathrm{Ng} \alpha$-CA. This quantitative analysis of HisND1-Zn distance and the conformation of catalytic histidine residues among $\mathrm{Ng} \alpha$-CA, Ssp $\alpha$-CA, and mutant $\mathrm{Ng} \alpha$-CA imply that the rate of proton shuttle is faster in both $\operatorname{Ssp} \alpha$-CA and mutant $\mathrm{Ng} \alpha$-CA. Faster proton shuffling results higher enzymatic activity of thermophilic Ssp $\alpha$-CA and mutant $\mathrm{Ng} \alpha$-CA, compared to the wildtype mesophilic $\mathrm{Ng} \alpha$-CA at a high temperature of $500 \mathrm{~K}$. The higher enzymatic activity of Ssp $\alpha$-CA and mutant $\mathrm{Ng} \alpha$-CA compared to that of wild-type $\mathrm{Ng} \alpha$-CA is also supported by the relative $\mathrm{p} K_{\mathrm{a}}$ values that we have estimated later and is in good agreement with the analysis of the HisND1-Zn distance from the MD simulation study.

Determination of the Melting Temperature $\left(T_{\mathrm{m}}\right)$. In this study, we have tried to complement the experimental evidence with one of the most efficient theoretical predictions. Here, we have theoretically calculated the denaturation temperature or $T_{\mathrm{m}}$ of mesophilic $\mathrm{Ng} \alpha$-CA, thermophilic Ssp $\alpha$-CA, and mutant $\mathrm{Ng}$ $\alpha$-CA, using the CNA. The method of $T_{\mathrm{m}}$ prediction can well mimic the experimental method of Circular Dichroism (CD), which determines the effects of mutations and ligands on protein and polypeptide stability with respect to the change in $\mathrm{CD}$ as a function of temperature. This also determines the enthalpy $(\Delta H)$ and entropy $(\Delta S)$ of unfolding, the midpoint of the unfolding transition (TM), and the free energy $(\Delta G)$ of unfolding (1). Likewise, in the $T_{\mathrm{m}}$ prediction method, a thermal unfolding simulation has been performed on each of the system. During the calculation of $T_{\mathrm{m}}$, two other order parameters have also been considered, which are protein's backbone rigidity and deformation energy for intraprotein hydrogen bonds. The unfolding transition calculated in $\mathrm{CD}$ is calibrated as a phase transition in the $T_{\mathrm{m}}$ prediction method (2). A comparative stability graph of the calibrated melting temperatures of the three proteins reveals that thermophilic Ssp $\alpha$-CA has the highest $T_{\mathrm{m}}$ among all, and it is $348 \mathrm{~K}\left(75^{\circ} \mathrm{C}\right)$, whereas its mesophilic counterpart $\mathrm{Ng} \alpha$-CA has the lowest $T_{\mathrm{m}}$ of $312 \mathrm{~K}$ (39 ${ }^{\circ} \mathrm{C}$ ) compared to the other two protein systems. Mutant $\mathrm{Ng} \alpha$ CA has a $T_{\mathrm{m}}$ of $333 \mathrm{~K}\left(60{ }^{\circ} \mathrm{C}\right)$, close to that of thermophilic Ssp $\alpha$-CA (Figure 8). The other two factors, rigidity and $\mathrm{H}$-bond energy, calculated along with the melting temperature are also in good agreement with the comparative stability of the above three proteins. The melting temperature actually defines the moment when the rigidity of the protein backbone and the $\mathrm{H}$ bond energy suddenly drop to a significantly low level. In the figure, the red bar indicates the melting temperature for individual proteins. It can be commented from the figure that mesophilic $\mathrm{Ng} \alpha$-CA starts to denature quickly than thermophilic Ssp $\alpha$-CA and mutant $\mathrm{Ng} \alpha$-CA. Thermophilic Ssp $\alpha$-CA is shown to retain its backbone rigidity the most, even at a high temperature of $348 \mathrm{~K}\left(75^{\circ} \mathrm{C}\right)$. Mutant $\mathrm{Ng} \alpha$-CA is also shown to contain more number of high-energy $\mathrm{H}$-bonds and a higher rigidity index up to a temperature of $333 \mathrm{~K}\left(60{ }^{\circ} \mathrm{C}\right)$, reflecting its greater stability than wild-type $\mathrm{Ng} \alpha$-CA.

\section{CONCLUSIONS}

In the current study, comparative MD simulation has been used for understanding the molecular basis of different thermostabilities in mesophilic and thermophilic $\alpha$-CA. Different stability comparing factors, such as RMSD, RMSF, $R_{\mathrm{g}}$, SASA, hydrogen bonds, salt bridges, secondary structure content, unfolding pathway, PCA, CNA, ED and FEL, $\mathrm{p} K_{a}$, melting temperature, have been detected for both the mesophilic and thermophilic $\alpha$-CA. Comparative analyses of those stabilitydetermining factors of mesophilic and thermophilic $\alpha$-CA guided us to develop a set of mutations in mesophilic $\alpha$-CA in search for increased thermostability. Finally, we have designed to induce three mutations (S44R, S139E, and K168R) in mesophilic $\alpha$-CA through a detailed analysis from sequence comparison, RMSF values, and detection of stabilizing and destabilizing salt bridges. All of the above-mentioned stabilitydetermining factors have also been analyzed for mutant $\alpha$-CA, and the results clearly show that the mutant becomes more thermostable than the wild type and becomes comparable to thermophilic $\alpha$-CA with regard to stability. Salt bridge analysis shows that mutant $\alpha$-CA evolves to form five new salt bridges that impart extra thermostability. In addition, the RMSD, RMSF, $R_{g}$, and SASA values for mutant $\alpha$-CA become reduced compared to the mesophilic one at higher temperatures. PCA shows that mutant $\alpha$-CA traverses through comparatively fewer conformational spaces than wild-type mesophilic $\alpha$-CA, representing greater structural rigidity of mutant $\alpha$-CA. The Comparative ED analysis of these three proteins explains the difference in thermal stability in accordance with PCA results. CNA also proves that the newly designed mutant $\alpha$-CA has a more compact interaction network compared to the wild-type protein. The FEL analysis shows that wild-type mesophilic $\alpha$-CA follows a constricted pathway from a native to a non-native state through less populated intermediate states. This actually supports the experimental observation regarding the irreversible folding-to-unfolding transition of wild-type mesophilic $\alpha$-CA at higher temperatures. The comparative FEL analysis reveals that mutant $\alpha$-CA has more number of native-like intermediate states with lower aggregation propensities compared to wild-type mesophilic $\alpha$-CA. This finding explains the variation in stabilities between mesophilic and mutant $\alpha$-CA, which is also in good agreement with other different analyses from the $\mathrm{MD}$ simulation trajectory. The newly designed mutant revealed that the improved stability has resulted from a reduced rate of protein 
unfolding and a decreased rate of precipitation of the unfolding intermediates. In contrast to mesophilic $\alpha$-CA, mutant $\alpha$-CA, like the thermophilic homologue, shows a deep and rugged FEL surface near the native state at $500 \mathrm{~K}$. Throughout the analysis of different states of FEL, we have shown that mutant $\alpha$-CA stays mostly in those conformations that retain stable salt bridges and hydrogen bonds. Such conformations help the mutant variant to remain stable even at extremely high temperatures. On the basis of the discussed results, we propose that mutant $\alpha$-CA possesses both structural rigidity required to adapt in high temperatures (like the thermophilic homologue) and flexibility in catalytically important regions (like its originator, mesophilic $\alpha$-CA) needed for optimum enzymatic activity at those high temperatures.

The in silico approach followed in this study provides new insights into protein engineering. Mutational study to understand or alter protein functions has been a very powerful tool for decades, but there is less correlation between the structural and functional roles of an amino acid. This frequently leads to the design of unstable proteins, resulting in poor or no expression of the mutant variants when treated experimentally. This clearly results in huge loss of manpower and money. The most interesting analyses of this study are the $\mathrm{p} K_{\mathrm{a}}$ calculation and the determination of melting temperature $\left(T_{\mathrm{m}}\right)$, both of which actually compensate for the experimental study. The $\mathrm{p} K_{\mathrm{a}}$ calculation shows that the designed mutant mesophilic $\alpha$-CA is a more active enzyme than the wild-type one, and the $T_{\mathrm{m}}$ calculation confirms its thermal stability as being close to that of thermophilic $\alpha$-CA. In future, this study would work as a platform not only to help further design thermally stable and industrially important proteins, which would be applicable in diverse biotechnological, pharmaceutical, and biomedical fields at relatively high temperatures, but also to provide a basis for designing mutants with better chance to be produced successfully under experimental conditions.

\section{MATERIALS AND METHODS}

Basis of Mutant Construction of $\boldsymbol{\alpha}$-CA. To construct a thermostable mutant $\alpha$-CA, we have gone through successive steps of analyzing the sequence, structure and then detecting its stability using MD simulations of the mutant protein. ${ }^{36,37} \mathrm{We}$ have first analyzed a number of comparative sequence and structural factors, such as number of proline and charged residues, total SASA, number of hydrogen bonds and salt bridges, for mesophilic and thermophilic $\alpha$-CA. ${ }^{38}$ From their corresponding sequence alignments, we have found that the number of proline residues is greater in the mesophilic $\alpha$-CA protein than that in the thermophilic one. Proline residues take part in secondary structure deformation and hence are mostly found in the loop region. Proline is also known for making the loops rigid. Structural analysis shows that thermophilic $\alpha$-CA has all its proline residues in the loop region, whereas in its mesophilic counterpart, two proline residues are excluded from the loop, and thus, we have hypothesized that they might have some role in destabilizing the secondary structure contents. Thermophilic $\alpha$-CA has more number of charged residues (Arg, Lys, Asp, and Glu) than its mesophilic homologue. In particular, there are more surface-oriented charged residues in the case of thermophilic $\alpha$-CA compared to the mesophilic one. ${ }^{39}$ The number of intrachain hydrogen bonds and salt bridges are also greater in thermophilic $\alpha$-CA. The total SASA is greater for mesophilic $\alpha$-CA than thermophilic, which implies rapid unpacking of the core hydrophobic region of the mesophilic protein than its thermophilic counterpart. All of the above results support the enhanced stability of thermophilic $\alpha$-CA over mesophilic $\alpha$-CA (Table 3).

\section{Table 3. Different Structural Factors of Protein Stability}

\begin{tabular}{lll}
\multicolumn{1}{c}{ factors } & \multicolumn{1}{c}{ mesophilic $\alpha$-CA } & \multicolumn{1}{c}{ thermophilic $\alpha$-CA } \\
total surface area & $12420 \AA^{2}$ & $11620 \AA^{2}$ \\
$\begin{array}{l}\text { number of hydrogen } \\
\text { bond }\end{array}$ & 487 & 526 \\
$\begin{array}{c}\text { number of salt } \\
\text { bridges }\end{array}$ & $\begin{array}{c}4 \text { (all confined in a local } \\
\text { region) }\end{array}$ & $\begin{array}{c}5 \text { (dispersed in different } \\
\text { places })\end{array}$ \\
$\begin{array}{c}\text { number of proline } \\
\text { residues }\end{array}$ & $15(13$ in loop) & 11 (all in loop) \\
charged residues & 44 & 62 \\
\hline
\end{tabular}

From the above sequence and structure-based analysis, we accumulate some ideas about the significant flexible region in the mesophilic protein compared to its thermophilic homologue, where we can introduce mutation to enhance its stability. We have first used the RMSF values obtained from the MD simulation to identify these types of flexible regions in mesophilic proteins. ${ }^{40}$ From the sequence alignment between mesophilic and thermophilic $\alpha$-CA, we have then further identified the residues in the mesophilic protein, which correspond to the salt bridge-forming residues in the thermophilic one. Then, we have selected the surrounding residues ( $8 \AA$ radius) of those individual mesophilic residues and have further compared the RMSF values of all of those residues with their thermophilic counterpart. We have found some residues of mesophilic $\alpha$-CA showing high RMSF values at all of the temperatures as compared to the thermophilic one. Residues of mesophilic $\alpha$-CA that show approximately two to four times greater RMSF than the corresponding thermophilic $\alpha$-CA residues are Ser44, Asn134, Arg136, Ser139, Trp141, Pro164, Arg166, Lys168, Tyr169, Arg171, Leu188, and Tyr193. In addition to that, in thermophilic $\alpha$-CA there is a compact network between the salt bridge-forming residues, such as Lys36, Lys39, Lys41, Glu99, Arg165, and Glu223. Structural analysis also revealed that the main differences between wildtype mesophilic $\alpha$-CA and its thermophilic homologue are the organization of salt bridges involved in the above-mentioned surface residues. The corresponding mesophilic $\alpha$-CA residues in this region are Glu41, Ser44, Lys102, Lys168, and Glu226, which show comparatively increased RMSF value at all temperatures. $^{41,42}$ Increased RMSF values might also be a reason for not forming any salt bridges in this region in the case of mesophilic $\alpha$-CA. We have also found some destabilizing salt bridges in the mesophilic protein, which are Lys102-Arg104, Arg136-Lys 165, Lys 165-Arg166, Arg166-Lys168, and Lys132-Arg136. The corresponding residues in the thermophilic protein for these positions are interestingly a pair of two oppositely charged residues. In thermophilic $\alpha$-CA, these pairs of residues are Glu99-Lys101, Glu133-Lys162, Lys162Asp163, Asp163-Arg165, and Lys129-Glu133 (Table 4). ${ }^{43}$ All of these residues of thermophilic $\alpha$-CA show significantly low RMSF values than the corresponding mesophilic $\alpha$-CA residues (Table 5). Glu99, Glu133, Asp163, and Arg165 from those pairs of oppositely charged residues are shown to form salt bridges in thermophilic $\alpha$-CA.

According to the significant changes in RMSF values and destabilizing salt bridges in the mesophilic protein, we have introduced some mutations. Our first choice of mutation is S44R because we have found that the residue Serine in this position of mesophilic $\alpha$-CA does not form any salt bridge, 
Table 4. Destabilizing Salt Bridge

$\begin{array}{cc}\begin{array}{c}\text { destabilizing salt bridge pair in } \\ \text { mesophilic } \alpha \text {-CA }\end{array} & \begin{array}{c}\text { corresponding residues pair in } \\ \text { thermophilic } \alpha \text {-CA }\end{array} \\ \text { Lys102-Arg104 } & \text { Glu99-Lys101 } \\ \text { Arg136-Lys165 } & \text { Glu133-Lys162 } \\ \text { Lys165-Arg166 } & \text { Lys162-Asp163 } \\ \text { Arg166-Lys168 } & \text { Asp163-Arg165 } \\ \text { Lys132-Arg136 } & \text { Lys129-Glu133 } \\ { }^{a} \text { Residues in bold form a salt bridge in both proteins. }\end{array}$

whereas at the same position, Lysine form a salt bridge with Glu223 in thermophilic $\alpha$-CA. Moreover, the RMSF value of Ser44 is about double in mesophilic $\alpha$-CA compared to Lys 41 of thermophilic $\alpha$-CA because of the absence of the salt bridge. By mutating Ser44 to arginine, we want to develop maximum number of salt bridges, contributing to higher stability. From the structure and chemistry of amino acids, it is known that the side chain of lysine contains only one charged amino group, whereas arginine has two. So, arginine has the potential of forming more number of salt bridges with surrounding oppositely charged residues. And our hypothesis is duly supported by the outcome. In the case of the mutant, Arg44 has formed three salt bridges with the Glu226 residue, whereas in the case of its thermophilic counterpart, two salt bridges were observed between Lys41 and Glu223. Moreover, the presence of more salt bridges between Arg44 and Glu226 in the mutant imparts higher rigidity to the system, enhancing the structural stability in comparison to its thermophilic counterpart. This could be confirmed by comparing the 400 and $500 \mathrm{~K} \mathrm{MD}$ simulation frames for thermophilic and mutant proteins. An increment in the distance between these two residues (Lys41 and Glu223) would be observed in the case of thermophilic proteins, whereas such an alternation is absent in the mutant protein. Because of the above-mentioned facts, we have decided to choose arginine over lysine in place of Ser44 to achieve better thermal stability for mutant $\alpha$-CA (Figure S10). Arg136 already forms salt bridges with Asp194 in mesophilic $\alpha$-CA, so we did not substitute it in spite of having two destabilizing salt bridge partners: Lys132 and Lys 165. Arg136 of mesophilic $\alpha$-CA shows larger RMSF than the corresponding salt bridge-forming residue Glu133 in thermophilic $\alpha$-CA. Searching for an alternative, we have found that by altering Ser 139 to Glutamate, there is a chance for the formation of a salt bridge between Arg136 and Glu139. The newly constructed salt bridge might have some effect to hold the destabilizing salt bridge partner Arg136 and thereby provide additional stability. We have predicted that the salt bridge between Glu139 and Arg136 might also make Glu139 less flexible in the designed mutant than the Ser139 in wild-type mesophilic $\alpha$-CA. In mesophilic $\alpha$-CA, the residue Lys 168 cannot form any salt bridge with its nearby oppositely charged residue Glu226 because it also has a destabilizing salt bridge partner Arg166. So, we have postulated that by constructing the mutant K168R, we might be able to diminish the effect of the destabilizing salt bridge (Figure S8). From the RMSF value, it can also be shown that Lys 168 of mesophilic $\alpha$-CA is larger than the corresponding Arg165 of the thermophilic protein, which also supports our approach to mutate Lys 168 to arginine. We have hypothesized that in the mutant, we might have a high probability of finding salt bridges between substituted residues Arg168 and Glu226, and this will play a key role in enhancing thermal stability. ${ }^{44}$

System-Setup. The crystal structures of two homologous $\alpha$ CA from mesophilic N. gonorrhoeae (PDB ID: $1 \mathrm{KOQ})^{21}$ and thermophilic Sulfurohydrogenibium sp. (PDB ID: 4G7A) ${ }^{22}$ were used as starting models for the MD simulations. ${ }^{45}$ Crystal structures of mesophilic and thermophilic $\alpha$-CA have resolutions of 1.80 and $1.90 \AA$ and the B-factors of 22.94 and $17 \AA^{2}$ with residue numbers $2-225$ and 5-226, respectively. We have performed $\mathrm{MD}$ simulations of both wild-type and mutant $\alpha$-CAs. We have introduced three mutations into mesophilic $\mathrm{Ng}$ $\alpha$-CA (S44R, S139E, and K168R) by using the COOT ${ }^{46}$ software. We have then performed MD simulations of mutant protein and have shown comparative thermal stabilities for both wild-type $\alpha$-CAs.

MD Simulation. We have used GROMACS $4.5 .4^{45}$ and OPLS-AA all atom force field ${ }^{47,48}$ for MD simulations, on an Intel Xeon Quad Core W3530 2.8 8 M 1366 Processor with LINUX environment. Mesophilic and thermophilic $\alpha$-CA were solvated in a cubic box (dimension with $74.8 \times 74.8 \times 74.8$ and $74.6 \times 74.6 \times 74.6$, respectively) filled with SPC216 water molecules (12 655 and 12604 , respectively). ${ }^{49}$ To simulate the solvated system in a neutral $\mathrm{pH}$, we have replaced solvent molecules with counter ions $\left(5 \mathrm{Cl}^{-}\right.$for mesophilic $\alpha$-CA and 11 $\mathrm{Cl}^{-}$for thermophilic $\alpha$-CA).

The steepest descent method of energy minimization was applied for all of the systems for an iteration cycle of maximum 50000 steps. $^{50}$ The minimized systems were then equilibrated at four different temperatures $(300,350,400$, and $500 \mathrm{~K})$ to relax the system and maintain the constant temperature and pressure of the system. A production run of $100 \mathrm{~ns}$ was performed. Periodic boundary conditions were applied under isothermal and isobaric conditions, using Berendsen coupling algorithm with relaxation times of 0.1 and $0.2 \mathrm{ps}$, respectively. ${ }^{51}$ The LINCS algorithm was used to constrain bond lengths using a time step of 2 fs for both systems. ${ }^{52}$ Electrostatic interactions

Table 5. Comparative RMSF of Residues Forming Destabilizing Salt Bridge and the Corresponding Thermophilic Residues

\begin{tabular}{|c|c|c|c|c|c|c|c|c|c|}
\hline \multirow[b]{2}{*}{ mesophilic $\alpha$-CA (M) } & \multirow[b]{2}{*}{ thermophilic $\alpha$-CA (T) } & \multicolumn{2}{|c|}{$300 \mathrm{~K}$} & \multicolumn{2}{|c|}{$350 \mathrm{~K}$} & \multicolumn{2}{|c|}{$400 \mathrm{~K}$} & \multicolumn{2}{|c|}{$500 \mathrm{~K}$} \\
\hline & & $\mathrm{M}$ & $\mathrm{T}$ & $\mathrm{M}$ & $\mathrm{T}$ & $\mathrm{M}$ & $\mathrm{T}$ & $\mathrm{M}$ & $\mathrm{T}$ \\
\hline Lys 102 & Glu99 & 0.1293 & 0.1388 & 0.1632 & 0.1921 & 0.1948 & 0.2436 & 0.4467 & 0.3085 \\
\hline Arg104 & Lys 101 & 0.0778 & 0.1777 & 0.1173 & 0.2029 & 0.1729 & 0.2314 & 0.3876 & 0.2895 \\
\hline Lys 132 & Lys 129 & 0.2391 & 0.1812 & 0.2182 & 0.1896 & 0.2709 & 0.198 & 0.5366 & 0.329 \\
\hline Arg136 & Glu133 & 0.2914 & 0.086 & 0.2896 & 0.0933 & 0.3214 & 0.1142 & 0.7206 & 0.3868 \\
\hline Lys 165 & Lys 162 & 0.2519 & 0.1952 & 0.2491 & 0.2053 & 0.2403 & 0.2226 & 0.7082 & 0.3132 \\
\hline $\operatorname{Arg} 166$ & Asp163 & 0.3193 & 0.0943 & 0.2513 & 0.1149 & 0.2589 & 0.1266 & 0.6994 & 0.2229 \\
\hline Lys 168 & Arg165 & 0.1765 & 0.0753 & 0.1638 & 0.166 & 0.1747 & 0.2322 & 0.5154 & 0.2847 \\
\hline
\end{tabular}

${ }^{a}$ RMSF values in bold represent comparatively less fluctuation of thermophilic residues corresponding to its mesophilic residues at the respective temperature. 
were calculated using the Particle Mesh Ewald method, and van der Waals and Coulombic interactions were calculated with a cutoff at $1.0 \mathrm{~nm} .^{53}$

The tools provided by the GROMACS package were utilized to analyze different MD trajectories. Secondary structure analyses were performed using the program DSSP. ${ }^{54}$ We used a web-based server 2 Struc ${ }^{55}$ that provides detailed information regarding secondary structures, including $\alpha$ helices, $3^{10}$ helices, $\beta$ strands, $\beta$ bridges, $\beta$ turns, and bends. Web server $\mathrm{ESBRI}^{56}$ was used for salt bridge calculation and PyMOL, ${ }^{57}$ Chimera, ${ }^{58}$ VMD, ${ }^{59} \mathrm{COOT}^{46}$ was used as the visualizing software. PyMOL $^{57}$ Xmgrace, $^{60}$ and MATLAB ${ }^{61}$ programs were used to analyze and prepare the figures.

We have analyzed the key order parameters that determine the molecular basis of the thermal stability for each of the wildtype mesophilic $\alpha$-CA, thermophilic $\alpha$-CA, and mutant mesophilic $\alpha$-CA. RMSD, RMSF, $R_{\mathrm{g}}$, and SASA have been calculated and analyzed for the determination of thermal stability and their differences. ${ }^{62}$

The salt bridges in both homologues of $\alpha$-CA protein were calculated using a web-based tool ESBRI, ${ }^{56}$ using a cutoff value of $4.0 \AA$ for salt bridge lengths. By comparing the salt bridges in both mesophilic and thermophilic $\alpha$-CA, we identified some extra salt bridges, which maintain greater stability in thermophilic $\alpha$-CA, and replaced the corresponding residues in mesophilic $\alpha$-CA without perturbing the salt bridges already present in wild-type mesophilic $\alpha$-CA. After introducing those residues, we have found that the initial structure of the mutant mesophilic $\alpha$-CA gained some extra salt bridges. In this way, we have designed a mutant mesophilic $\alpha$-CA containing three mutations (S44R, S139E, and K168R) (Figure 6). Then, we investigated the increasing thermostability due to the newly originated salt bridges in mutant $\alpha$-CA. We have also analyzed the variation of salt bridge length in all of the $\alpha$-CA systems as a function of different temperatures. The length variation of salt bridges was analyzed with respect to the average PDB at a given temperature. Improvement of the side chain conformation of each residue from all of the average PDBs was performed using Scwrl4. ${ }^{63}$

The covariance matrices of the positional fluctuations of $\mathrm{C}_{\alpha}$ atoms were analyzed with PCA or ED. ${ }^{64,65}$ The first two principal components (PC1, PC2) contribute to the major protein backbone motion and have been used for the PCA. The covariance matrix was diagonalized to obtain the eigenvectors and eigenvalues that provide information about correlated motions throughout the protein. The FEL prepared using MATLAB $^{61}$ describes the energy distribution and biological interrelation between thermodynamics and protein stability.

\section{ASSOCIATED CONTENT}

\section{S Supporting Information}

The Supporting Information is available free of charge on the ACS Publications website at DOI: 10.1021/acsomega.6b00041.

Additional discussion, supplementary figures and tables (PDF)

Dynamics of mesophilic NgCA (AVI)

Dynamics of thermophilic Ssp-CA (AVI)

Dynamics of mutant NgCA (AVI)

\section{AUTHOR INFORMATION}

\section{Corresponding Authors}

*E-mail: sdattfbt@iitr.ac.in (S.D.).
*E-mail: shazrfbt@iitr.ac.in, saugata.iitk@gmail.com (S.H.).

\section{Author Contributions}

${ }^{\perp}$ S.K.B., M.H., and M.P. contributed equally.

\section{Notes}

The authors declare no competing financial interest.

\section{ACKNOWLEDGMENTS}

A part of the work was conducted in the context of the SFI/HEA Irish Centre for High-End Computing (ICHEC), ICC, IITRoorkee, Bioinformatics Facility, Department of Biotechnology, IIT-Roorkee, Bioinformatics Resources and Applications Facility (BRAF), C-DAC, Pune for the provision of computational facilities and support.

\section{REFERENCES}

(1) Retrofitting of Coal-Fired Power Plants for $\mathrm{CO}_{2}$ Emissions Reductions; MIT Energy Initiative Massachusetts Institute of Technology, 23rd March, 2009. http://news.mit.edu/2009/whitepaper.pdf.

(2) Yu, C. A. Review of $\mathrm{CO}_{2}$ Capture by Absorption and Adsorption; Aerosol and Air Quality Research, 2012; Vol. 12, pp 745-769.

(3) Advanced Post-Combustion $\mathrm{CO}_{2}$ Capture, 1st ed., April 2009. https://sequestration.mit.edu/pdf/Advanced_Post_Combustion_ CO2_Capture.pdf.

(4) Kanbar, B. Enzymatic $\mathrm{CO}_{2}$ Sequestration by Carbonic Anhydrase, 1st ed., 2008. http://openaccess.iyte.edu.tr/bitstream/handle/11147/ 3957/T000767.pdf? sequence $=1$.

(5) Supuran, C. Carbonic Anhydrases An Overview. Curr. Pharm. Des. 2008, 14, 603-614.

(6) Domsic, J.; McKenna, R. Sequestration Of Carbon Dioxide By The Hydrophobic Pocket Of The Carbonic Anhydrases. Biochim. Biophys. Acta, Proteins Proteomics 2010, 1804, 326-331.

(7) Tripp, B.; Smith, K.; Ferry, J. Carbonic Anhydrase: New Insights For An Ancient Enzyme. J. Biol. Chem. 2001, 276, 48615-48618.

(8) Kararli, T.; Silverman, D. Kinetics Of The Hydration Of $\mathrm{CO}_{2}$ Catalyzed By Carbonic Anhydrase III From Skeletal Muscle Of The Cat. Ann. N.Y. Acad. Sci. 1984, 429, 129-136.

(9) Wells, J.; Kandel, S.; Koenig, S. The pH Dependence Of Solvent Proton Relaxation In Carbonic Anhydrase Solutions: Paramagnetic And Diamagnetic Effects. Biochemistry 1979, 18, 1989-1995.

(10) Villafuerte, F.; Swietach, P.; Patiar, S.; Harris, A.; Vaughan-Jones, R. Comparison Of Ph-Dependence Of Carbonic Anhydrase Activity In Vitro And In Living Cells. Biophys. J. 2009, 96, 625a.

(11) Peirce, S.; Russo, M.; De Luca, V.; Capasso, C.; Rossi, M.; Olivieri, G.; Salatino, P.; Marzocchella, A. Immobilization Of Carbonic Anhydrase For Biomimetic CO2 Capture In Slurry Absorber. New Biotechnol. 2014, 31, S20-S21.

(12) Research and Development Goals for $\mathrm{CO}_{2}$ Capture Technology; U.S. Department of Energy: Washington, DC, 2011. https://www.netl.doe. gov/ e n e r g y - a n a lys e s / t e m p /

ResearchandDevelopmentGoalsforCO2CaptureTechnology_120111. pdf.

(13) Krishnamurthy, V.; Kaufman, G.; Urbach, A.; Gitlin, I.; Gudiksen, K.; Weibel, D.; Whitesides, G. Carbonic Anhydrase As A Model For Biophysical And Physical-Organic Studies Of Proteins And Protein-Ligand Binding. Chem. Rev. 2008, 108, 946-1051.

(14) Smith, K. Prokaryotic Carbonic Anhydrases. FEMS Microbiol. Rev. 2000, 24, 335-366.

(15) Smith, K.; Jakubzick, C.; Whittam, T.; Ferry, J. Carbonic Anhydrase Is An Ancient Enzyme Widespread In Prokaryotes. Proc. Natl. Acad. Sci. U.S.A. 1999, 96, 15184-15189.

(16) Capasso, C.; Supuran, C. An Overview Of The Alpha-, Beta- And Gamma-Carbonic Anhydrases From Bacteria: Can Bacterial Carbonic Anhydrases Shed New Light On Evolution Of Bacteria? J. Enzyme Inhib. Med. Chem. 2015, 30, 325-332.

(17) Liljas, A.; Laurberg, M. A Wheel Invented Three Times. EMBO Rep. 2000, 1, 16-17. 
(18) Hewett-Emmett, D.; Tashian, R. Functional Diversity, Conservation, And Convergence In The Evolution Of The Alpha-, Beta- And Gamma- Carbonic Anhydrase Gene Families. Mol. Phylogenet. Evol. 1996, 5, 50-77.

(19) Lindskog, S. Structure And Mechanism Of Carbonic Anhydrase. Pharmacol. Ther. 1997, 74, 1-20.

(20) Scozzafava, A.; Passaponti, M.; Supuran, C.; Gülçin, İ. Carbonic Anhydrase Inhibitors: Guaiacol And Catechol Derivatives Effectively Inhibit Certain Human Carbonic Anhydrase Isoenzymes (Hca I, II, IX And XII). J. Enzyme Inhib. Med. Chem. 2015, 30, 586-591.

(21) Huang, S.; Xue, Y.; Sauer-Eriksson, E.; Chirica, L.; Lindskog, S.; Jonsson, B. Crystal Structure Of Carbonic Anhydrase From Neisseria gonorrhoeae And Its Complex With The Inhibitor Acetazolamide. J. Mol. Biol. 1998, 283, 301-310.

(22) Di Fiore, A.; Capasso, C.; De Luca, V.; Monti, S.; Carginale, V.; Supuran, C.; Scozzafava, A.; Pedone, C.; Rossi, M.; De Simone, G. Xray structure of the first 'extremo- $\alpha$-carbonic anhydrase', a dimeric enzyme from the thermophilic bacterium Sulfurihydrogenibium yellowstonense YO3AOP1. Acta Crystallogr., Sect. D: Biol. Crystallogr. 2013, 69, 1150-1159.

(23) Capasso, C.; De Luca, V.; Carginale, V.; Cannio, R.; Rossi, M. Biochemical Properties Of A Novel And Highly Thermostable Bacterial Alpha-Carbonic Anhydrase From Sulfurihydrogenibium Yellowstonense YO3AOP1. J. Enzyme Inhib. Med. Chem. 2012, 27, 892-897.

(24) Missimer, J.; Steinmetz, M.; Baron, R.; Winkler, F.; Kammerer, R.; Daura, X.; van Gunsteren, W. Configurational Entropy Elucidates The Role Of Salt-Bridge Networks In Protein Thermostability. Protein Sci. 2007, 16, 1349-1359.

(25) Chan, C.; Yu, T.; Wong, K. Stabilizing Salt-Bridge Enhances Protein Thermostability By Reducing The Heat Capacity Change Of Unfolding. PLoS One 2011, 6, No. e21624.

(26) Boone, C.; Habibzadegan, A.; Tu, C.; Silverman, D.; McKenna, R. Structural And Catalytic Characterization Of A Thermally Stable And Acid-Stable Variant Of Human Carbonic Anhydrase II Containing An Engineered Disulfide Bond. Acta Crystallogr., Sect. D: Biol. Crystallogr. 2013, 69, 1414-1422.

(27) Fisher, S.; Maupin, C.; Budayova-Spano, M.; Govindasamy, L.; Tu, C.; Agbandje-McKenna, M.; Silverman, D.; Voth, G.; McKenna, R. Atomic Crystal And Molecular Dynamics Simulation Structures Of Human Carbonic Anhydrase II: Insights Into The Proton Transfer Mechanism. Biochemistry 2007, 46, 2930-2937.

(28) Lu, D.; Voth, G. Molecular Dynamics Simulations Of Human Carbonic Anhydrase II: Insight Into Experimental Results And The Role Of Solvation. Proteins: Struct., Funct., Genet. 1998, 33, 119-134.

(29) Gan, W.; Roux, B. Folding Pathway And Free Energy Landscape Of Villin Headpiece Subdomain HP35 Studied By String Method. Biophys. J. 2009, 96, 590a-591a.

(30) Singh, B.; Bulusu, G.; Mitra, A. Understanding The Thermostability And Activity Of Bacillus Subtilis Lipase Mutants: Insights From Molecular Dynamics Simulations. J. Phys. Chem. B. 2015, 119, 392-409.

(31) Kumar, S.; Tsai, C.; Nussinov, R. Factors Enhancing Protein Thermostability. Protein Eng., Des. Sel. 2000, 13, 179-191.

(32) Bae, E.; Phillips, G. Identifying and engineering ion pairs in adenylate kinases. Insights from molecular dynamics simulations of thermophilic and mesophilic homologues. J. Biol. Chem. 2005, 280, 30943-30948.

(33) Bernardi, R.; Cann, I.; Schulten, K. Molecular Dynamics Study Of Enhanced Man5b Enzymatic Activity. Biotechnol. Biofuels 2014, 7, 83.

(34) Ohta, S.; Alam, M.; Arakawa, H.; Ikai, A. Origin Of Mechanical Strength Of Bovine Carbonic Anhydrase Studied By Molecular Dynamics Simulation. Biophys. J. 2004, 87, 4007-4020.

(35) Lee, K. Molecular Dynamics Simulations Of A Hyperthermophilic And A Mesophilic Protein L30e. J. Chem. Inf. Model. 2012, 52, 7-15.

(36) Tang, L.; Liu, H. A Comparative Molecular Dynamics Study Of Thermophilic And Mesophilic Ribonuclease HI Enzymes. J. Biomol. Struct. Dyn. 2007, 24, 379-392.
(37) Damborsky, J.; Brezovsky, J. Computational Tools For Designing And Engineering Enzymes. Curr. Opin. Chem. Biol. 2014, 19, 8-16.

(38) Usher, K.; De La Cruz, A.; Dahlquist, F.; James Remington, S.; Swanson, R.; Simon, M. Crystal Structures Of Chey From Thermotoga Maritima Do Not Support Conventional Explanations For The Structural Basis Of Enhanced Thermostability. Protein Sci. 1998, 7, 403-412.

(39) Emond, S.; André, I.; Jaziri, K.; Potocki-Véronèse, G.; Mondon, P.; Bouayadi, K.; Kharrat, H.; Monsan, P.; Remaud-Simeon, M. Combinatorial Engineering To Enhance Thermostability Of Amylosucrase. Prot. Sci. 2008, 17, 967-976.

(40) Pikkemaat, M.; Linssen, A.; Berendsen, H.; Janssen, D. Molecular Dynamics Simulations As A Tool For Improving Protein Stability. Protein Eng., Des. Sel. 2002, 15, 185-192.

(41) Hazra, S.; Xu, H.; Blanchard, J.; Tebipenem, A. New Carbapenem Antibiotic, Is A Slow Substrate That Inhibits The BetaLactamase From Mycobacterium Tuberculosis. Biochemistry 2014, 53, $3671-3678$.

(42) Hazra, S.; Kurz, S.; Wolff, K.; Nguyen, L.; Bonomo, R.; Blanchard, J. Kinetic And Structural Characterization Of The Interaction Of 6-Methylidene Penem 2 With The Beta-Lactamase From Mycobacterium Tuberculosis. Biochemistry 2015, 54, 56575664.

(43) Kurz, S.; Hazra, S.; Bethel, C.; Romagnoli, C.; Caselli, E.; Prati, F.; Blanchard, J.; Bonomo, R. Inhibiting The Beta-Lactamase Of Mycobacterium Tuberculosis (Mtb) With Novel Boronic Acid Transition-State Inhibitors (Batsis). ACS Infect. Dis. 2015, 1, 234-242.

(44) Papaleo, E.; Pasi, M.; Tiberti, M.; De Gioia, L. Molecular Dynamics Of Mesophilic-Like Mutants Of A Cold-Adapted Enzyme: Insights Into Distal Effects Induced By The Mutations. PLoS One 2011, 6, No. e24214.

(45) Hess, B.; Kutzner, C.; van der Spoel, D.; Lindahl, E. GROMACS 4: Algorithms For Highly Efficient, Load-Balanced, And Scalable Molecular Simulation. J. Chem. Theory Comput. 2008, 4, 435-447.

(46) Emsley, P.; Cowtan, K. Coot : Model-Building Tools For Molecular Graphics. Acta Crystallogr., Sect. D: Biol. Crystallogr. 2004, 60, $2126-2132$

(47) Huang, J.; Sun, C.; Mitchell, O.; Ng, N.; Wang, Z.; Boutis, G. On The Inverse Temperature Transition And Development Of An Entropic Elastomeric Force Of The Elastin Mimetic Peptide [LGGVG] $(3,7)$. J. Chem. Phys. 2012, 136, No. 085101.

(48) Pronk, S.; Pall, S.; Schulz, R; Larsson, P.; Bjelkmar, P.; Apostolov, R.; Shirts, M.; Smith, J.; Kasson, P.; van der Spoel, D.; Hess, B.; Lindahl, E. GROMACS 4.5: A High-Throughput And Highly Parallel Open Source Molecular Simulation Toolkit. Bioinformatics 2013, 29, 845-854.

(49) Miyamoto, S.; Kollman, P. Settle: An Analytical Version Of The Shake And Rattle Algorithm For Rigid Water Models. J. Comput. Chem. 1992, 13, 952-962.

(50) Kundu, S.; Roy, D. Comparative Structural Studies Of Psychrophilic And Mesophilic Protein Homologues By Molecular Dynamics Simulation. J. Mol. Graphics Modell. 2009, 27, 871-880.

(51) Weber, W.; Hünenberger, P.; McCammon, J. Molecular Dynamics Simulations Of A Polyalanine Octapeptide Under Ewald Boundary Conditions: Influence Of Artificial Periodicity On Peptide Conformation. J. Phys. Chem. B 2000, 104, 3668-3675.

(52) Hess, B.; Bekker, H.; Berendsen, H.; Fraaije, J. LINCS: A Linear Constraint Solver For Molecular Simulations. J. Comput. Chem. 1997, $18,1463-1472$.

(53) Darden, T.; Perera, L.; Li, L.; Pedersen, L. New Tricks For Modelers From The Crystallography Toolkit: The Particle Mesh Ewald Algorithm And Its Use In Nucleic Acid Simulations. Structure 1999, 7, R55-R60.

(54) Kabsch, W.; Sander, C. Dictionary Of Protein Secondary Structure: Pattern Recognition Of Hydrogen-Bonded And Geometrical Features. Biopolymers 1983, 22, 2577-2637.

(55) Klose, D.; Wallace, B.; Janes, R. 2Struc: The Secondary Structure Server. Bioinformatics 2010, 26, 2624-2625. 
(56) Costantini, S.; Colonna, G.; Facchiano, A. ESBRI: A Web Server For Evaluating Salt Bridges In Proteins. Bioinformation 2008, 3, 137138.

(57) DeLano, W. The Pymol Molecular Graphics System; DeLano Scientific: San Carlos, CA, 2002. http://www.pymol.org.

(58) Pettersen, E.; Goddard, T.; Huang, C.; Couch, G.; Greenblatt, D.; Meng, E.; Ferrin, T. UCSF Chimera: A Visualization System For Exploratory Research And Analysis. J. Comput. Chem. 2004, 25, 16051612.

(59) Humphrey, W.; Dalke, A.; Schulten, K. VMD: Visual Molecular Dynamics. J. Mol. Graphics 1996, 14, 33-38.

(60) Vaught, A. Graphing with Gnuplot and Xmgr: Two graphing packages available under Linux. Linux J. 1996, 1996, 7. http://dl.acm. org $/$ citation.cfm? Id $=326334$.

(61) MATLAB R2014b; The MathWorks Inc.: Natick, MA, 2014.

(62) Paul, M.; Hazra, M.; Barman, A.; Hazra, S. Comparative Molecular Dynamics Simulation Studies For Determining Factors Contributing To The Thermostability Of Chemotaxis Protein "CheY". J. Biomol. Struct. Dyn. 2014, 32, 928-949.

(63) Krivov, G.; Shapovalov, M.; Dunbrack, R. Improved Prediction Of Protein Side-Chain Conformations With SCWRL4. Proteins 2009, 77, 778-795.

(64) Amadei, A.; Ceruso, M.; Di Nola, A. On The Convergence Of The Conformational Coordinates Basis Set Obtained By The Essential Dynamics Analysis Of Proteins' Molecular Dynamics Simulations. Proteins: Struct., Funct., Bioinf. 1999, 36, 419-424.

(65) Amadei, A.; Linssen, A.; Berendsen, H. Essential Dynamics Of Proteins. Proteins: Struct., Funct., Bioinf. 1993, 17, 412-425. 